\title{
Parametric Analysis of Slotting Operation Induced Failure Zones to Stimulate Low Permeability Coal Seams
}

\author{
Guangyao Si ${ }^{1,2}$ - Sevket Durucan ${ }^{1} \cdot \mathrm{Ji}^{-}$Quan $\mathrm{Shi}^{1} \cdot$ Anna Korre $^{1} \cdot$ Wenzhuo Cao $^{1}$
}

Received: 30 May 2018 / Accepted: 13 August 2018 / Published online: 3 September 2018

(c) The Author(s) 2018

\begin{abstract}
The main constrain for effective gas drainage in coal mines is the low permeability nature of coal reservoirs. As coal mining activities are extending to deeper subsurface, the ever-increasing in situ stress conditions is anticipated to result in much lower permeability and more challenges for gas emission control in coal mines. In recent years, hydraulic slotting using high-pressure waterjet along underground gas drainage boreholes, as a general solution to stimulate low permeability coal seams, has become increasingly favourable. This paper presents a systematic investigation into the sensitivity of borehole slotting performance to a number of field and operational parameters. A wide range of geomechanical properties, in situ stress conditions, slot geometry and spacing of multiple slots were considered in a series of numerical simulations. The relations between these key parameters and the failure zone size/volume induced by slotting were quantified. The effect of different parameters in improving slotting performance has also been ranked, which provides theoretical base for mine operators to optimise slotting operations.
\end{abstract}

Keywords Parametric analysis $\cdot$ Borehole slotting $\cdot$ Permeability stimulation $\cdot$ Numerical modelling

\section{Introduction}

Coal mining is extending to deeper and deeper levels, facing ever increasing coal seam methane contents, higher methane emissions and gas outburst risks at production districts. Increased gas content of coal seams with depth, and the concentration of coal exploitation in fewer high productivity faces in recent years, have been the major cause of

The work was conducted at the Imperial College when he was a Research Associate there. In December 2017, Guangyao moved to Australia to take the Lecturer position at the School of Minerals and Energy Resources Engineering, the University of New South Wales.

\section{Guangyao Si \\ g.si@unsw.edu.au \\ $\square$ Sevket Durucan \\ s.durucan@imperial.ac.uk}

1 Department of Earth Science and Engineering, Royal School of Mines, Imperial College, London SW7 2AZ, UK

2 Present Address: School of Minerals and Energy Resources Engineering, University of New South Wales, Room 159B, 1st Floor, Old Main Building, Kensington, Sydney, NSW, Australia the significant increase seen in methane emissions per ton of average coal output in Europe. Unfortunately, the large increase in methane emissions experienced in recent years was not matched with a similar increase in the efficiency of methane drainage systems. The increased release of methane observed with increasing depth is not only a serious safety risk, but also represents a problem for coal production, as it limits the advance rates of both development headings and longwall faces.

It has long been recognised that gas drainage boreholes deployed from the underground or surface to capture coal seam gas before it migrates into the ventilation air or atmosphere can provide a feasible solution to the gas emission problem. However, the primary limitation of applying methane drainage systems to reduce emissions in coal mining comes from the low permeability nature of coal seam reservoirs. For example, in some European coal basins, the permeability is reported to be as low as $10^{-21} \mathrm{~m}^{2}$, and normally in the range of $10^{-17}-10^{-12} \mathrm{~m}^{2}$ (Durucan and Edwards 1986). Except for the Qinshui Basin, coal permeability in China, the largest coal producer and consumer in the world, is generally very low $\left(10^{-19}-10^{-18} \mathrm{~m}^{2}\right)$, about four orders of magnitude lower than that of some US coals (Cheng et al. 2011). Gas pre-drainage from boreholes drilled into these 
low permeability coal seams is usually ineffective due to extremely low gas flow rates. This situation may be further exacerbated as a result of relatively short life-span of underground drainage boreholes.

Coal production can significantly alter stress conditions and, consequently, affect permeability around mine openings as permeability in coal is highly stress-dependent (e.g., Somerton et al. 1975; Durucan and Edwards 1986). Understanding of this process, as early as the 1950s in Europe, led to the development of cross-measure borehole drainage method, utilising the stress and permeability changes around mined seams to enhance gas production from mining-induced high permeability zones in multi-seam layouts.

By coupling geomechanical and reservoir simulators, Karacan et al. (2007a) assessed the performance of goaf wells in the Pittsburgh coal field and the impact of completion practices on optimising goaf gas production. Gas drainage performance from in-seam horizontal boreholes with different borehole patterns, borehole lengths, and leading times were also evaluated by the same coupling approach (Karacan et al. 2007b). After analysing stress changes, fracturing, and gas flow patterns in the mining of multi-seams, Guo et al. (2012) found that there is a three-dimensional ring in the overburden along the perimeter of the longwall panel, which can be used to maximise gas drainage performance. Kong et al. (2014) suggested a sequential approach to control gas emissions from multi-layer gassy coal seams by applying both surface and inclined cross-measure boreholes into the mining-induced high permeability areas. Gas emission and flow patterns in thick seam mining have been investigated through extensive field measurements and numerical simulations, which provides essential guidance for gas drainage design in ultra-thick coal seams (Si 2015; Si et al. 2015a, b). In the US, goaf gas venthole production was found to be largely enhanced due to stress-relief fracturing and bedding plane separation during the period of longwall face advance (Karacan 2015).

Although the concept of utilising mining-induced stress change to enhance gas production has achieved significant success, the applicability of this approach has been limited to specific geological and economic considerations. In recent years, primarily motivated by improving coal mining safety, slotting of gas drainage boreholes via hydraulic or mechanical force as a general solution to increase permeability, reduce gas emission, and prevent coal and gas outbursts has attracted increasing attention in China (Lu et al. 2009; Li et al. 2009; Lin and Shen 2015). This method involves creating multiple slots along uncased underground gas drainage boreholes to relieve near wellbore stresses, initiate fractures, and increase gas release surfaces.

One early study presented by Lu et al. (2009) introduced the development of a waterjet slotting system and its application in methane drainage boreholes at a Chinese colliery. They found that the captured methane concentration increased by up to 3-6 times after the slotting treatment. A new drilling technique using high pressure pulsed waterjet was proposed by Lu et al. (2010), whereby slotting of the borehole can be achieved simultaneously during drilling. Boreholes drilled using this technique were found to be 2.7 times longer with 5 times more gas produced compared with the boreholes drilled by conventional methods. The slotting technique was also applied in preventing coal and gas outbursts in China. Lu et al. (2011) reported its application in an outburst-prone soft coal seam as a measure to reduce in situ gas content and ensure the safety of driving longwall entries. In their paper, slot penetration depth, slot thickness and slot spacing were studied, and slot depth was found to be the main factor affecting stress relief and fracture zone around a borehole. An application of using hydraulic slotting at cross-measure drainage boreholes to prevent coal and gas outbursts was also discussed by Lin et al. (2015), where they reported that the required drainage period was reduced from 6 to 4 months. A positive relationship between the mass of coal discharged in outbursts and total amount of emitted gas was also observed.

Lin and Shen (2015) used multilevel waterjet slotting to stimulate gas drainage performance in Guhansan coal mine in China. Through laboratory experiments and numerical modelling, they reported that, by increasing the number of slots, multilevel slotting can significantly reduce coal strength and contribute to fracture coalescence. By considering a stress-dependent permeability relationship, the effectiveness of waterjet slotting in coal seams has been evaluated by Shen et al. (2015). The fluid flow module in $\mathrm{FLAC}^{3 \mathrm{D}}$ was used to assess stress, pressure, and permeability distributions around slotted boreholes. To assess crack evolution during the process of hydraulic slotting from a mesoscopic perspective, particle flow code $\mathrm{PFC}^{2 \mathrm{D}}$ was used in developing a laboratory scale model (Liu et al. 2015). Using numerical models and field experiments, Yang et al. (2016) concluded that there is an optimal value of coal discharge in slotting operations: too little coal discharge suggests not enough stimulation while too much coal discharge may be timeconsuming and lead to borehole collapse. Another interesting observation reported by Lin et al. (2015) and Yang et al. (2016) was that large coal discharge volume from the borehole can certainly increase the near borehole permeability as well as gas production rates. A fully coupled thermal-hydromechanical model was developed by Gao et al. (2016) to evaluate the gas drainage performance in slotted boreholes. More recently, Lin et al. (2018) suggested that the effectiveness of waterjet slotting is determined by both the static in situ stress and dynamic waterjet impact loading.

The above-mentioned investigations have set encouraging examples on the field application of the slotting technique in stimulating drainage boreholes and stress relieving coal 
seams. The effectiveness of slotting operations is reflected in the slotting-induced failure zone size, which is largely controlled by the in situ stress conditions and coal properties. In engineering practice, slot geometry and spacing need to be optimised to maximise the failure zone size and, consequently, the gas drainage performance. Currently, most of the borehole slotting stimulation designs are based on field experience or operators' judgement. On the other hand, to the authors' best knowledge, there is no systematic investigation on assessing the sensitivity of the key parameters and their role in controlling slotting performance, which limits the effectiveness and efficiency of borehole slotting and its application by the coal industry worldwide (Si et al. 2017).

In the research presented here, the impact of prevailing stress conditions, coal properties, and slot geometry and spacing of multiple slots on drainage borehole slotting performance were investigated through numerical modelling. By performing sensitivity analysis, the critical parameters controlling slotting operations are identified towards achieving an optimal slotting performance.

\section{Background}

Current research at Imperial College is investigating the potential benefits of the use of slotted boreholes in improving gas drainage performance and reducing the risk of coal and gas outbursts at different mining settings in the Spanish and Polish coalfields. One of the field sites considered for the implementation of slotted boreholes is the Montsacro Colliery, which operates in the Central Asturian coal basin, Northern Spain. The mineable coal seams in Montsacro are concentrated in Westphalian continental sediments (Suárez-Ruiz and Jiménez 2004), which has three seam series namely Esperanza, Pudingas, and Canales (Aguado and Nicieza 2007). The Canales series contains the $8 \#$ coal seam with a total thickness of $15.13 \mathrm{~m}$ at Montsacro, and this seam is responsible for many outburst incidents at the mine. The geological map of the Montsacro area is shown in Fig. 1, which suggests a strong tectonic movement history in the mining region. The tectonosedimentary evolution of the Central Asturian coal basin results in a high friable and foliated $8 \#$ coal seam, and the coal is also subject to the sudden variations in thickness and bed-parallel shearing, which largely increase the outburst risk at the mine (Aguado and Nicieza 2007).

The mine is characterised by high methane content and outburst prone coal seams. Due to the mine is in an anticline region with steeply dipping nature of most of the coal seams (over $45^{\circ}$ ) in the coalfield, unlike prevailing longwall or room and pillar mining methods applied in horizontal coal deposits, the mining method used here is sublevel caving (SLC), as illustrated in Fig. 2. From top to the bottom, the entire coal deposit is divided into series of mining levels. Between two levels, three to four sublevels are normally planned, and each level is approximately $20 \mathrm{~m}$ high. A crosscut entry to access each sublevel needs to be developed from the footwall to the central of that sublevel. Then two drifts aiming to recover the two wings of that sublevel are developed towards opposite directions. Sublevels are caved by drill and blasting, with the face retreating from the boundaries of the mining block towards the central cross-cuts, along the sublevel drifts. While coal extraction is undergoing in the current sublevel, drift accesses for successive faces in
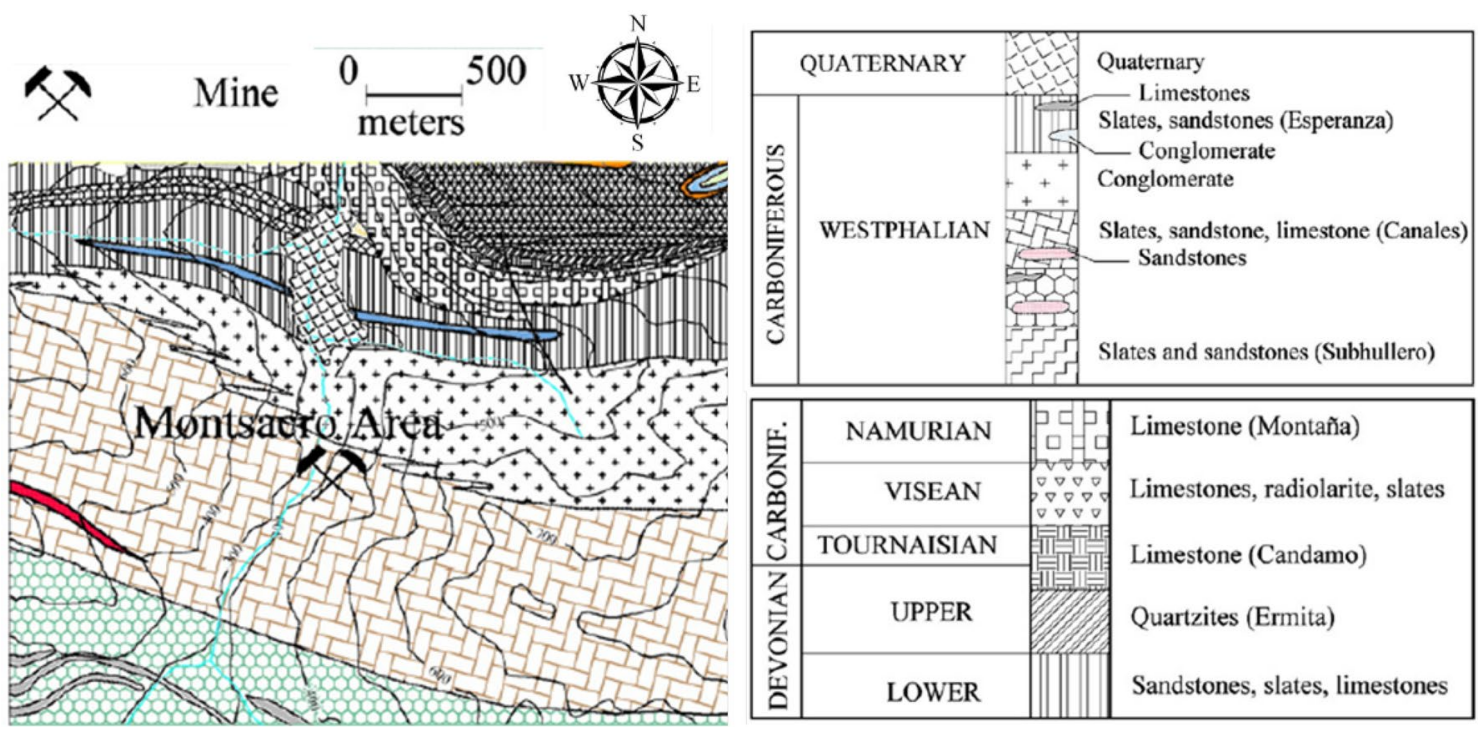

Fig. 1 Geological map at the Montsacro Colliery (modified after Aguado and Nicieza 2007) 


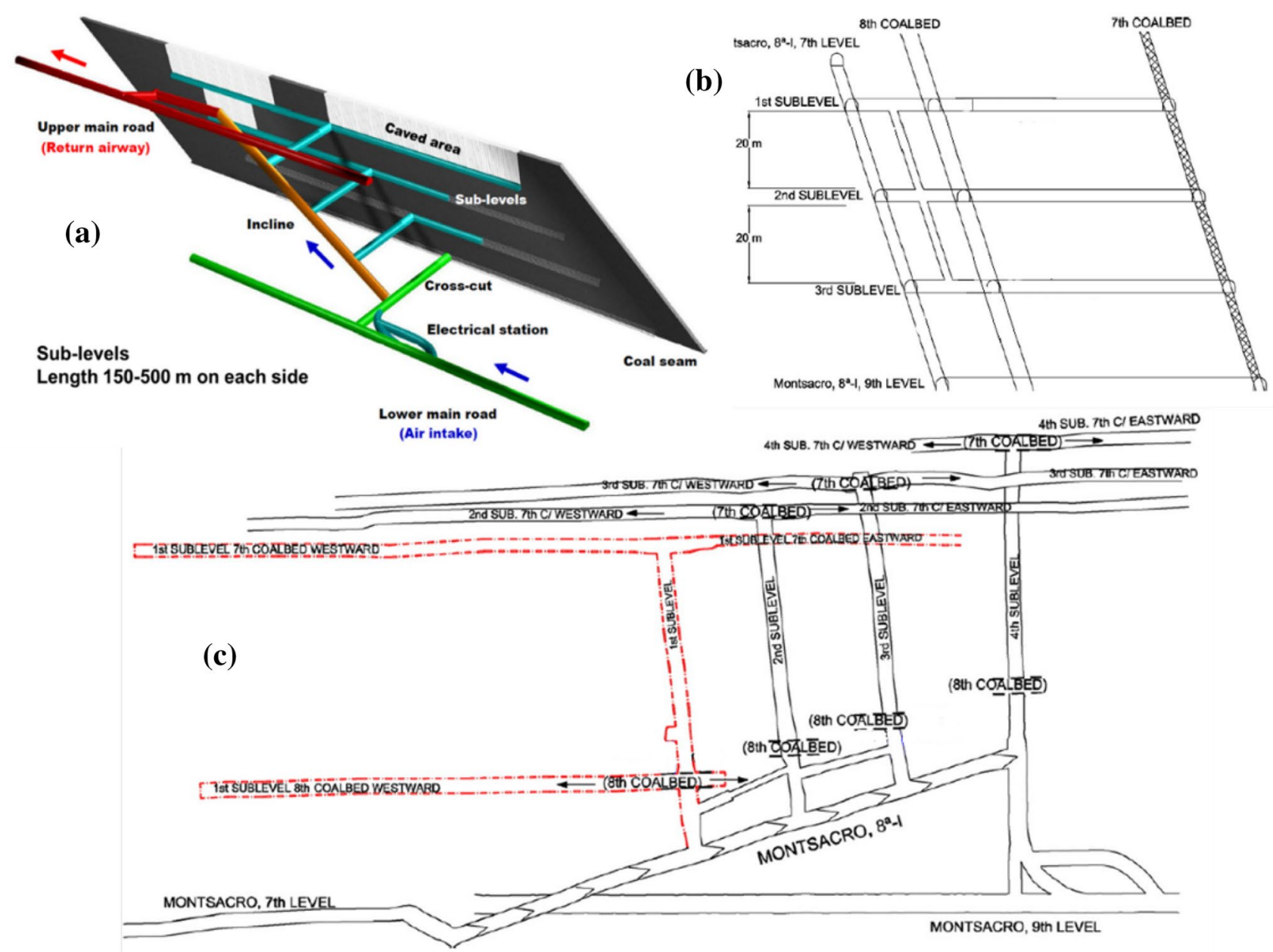

Fig. 2 a A schematic of the sublevel caving (SLC) mining method applied at Montsacro Colliery (not to scale); $\mathbf{b}$ front view and $\mathbf{c}$ plane view of mine plan at Montsacro Colliery (modified after Aguado and Nicieza 2007)

lower sublevels need to be developed. After the completion of current sublevel, coal production can start immediately from the successive sublevels without any delay.

The coal seam currently being-mined at Montsacro Colliery is the \#8 coal seam, which is $\sim 4.5 \mathrm{~m}$ thick and dipping at an angle of $72^{\circ}$. The hangingwall and footwall of this coal seam are both sandy slate. The coal is extremely friable and brittle in behaviour (Fig. 3). In situ stress measurements at the mine have indicated that the maximum principal stress is horizontal, most likely perpendicular to the strike of the coal seam. At $500 \mathrm{~m}$ depth, the maximum horizontal stress, minimum horizontal stress, and vertical stress were measured as 24,16 , and $12 \mathrm{MPa}$, respectively. Although this research focus on mining level at $500 \mathrm{~m}$ depth, the vertical down dip depth of the \#8 coal seam can be as much as $900-1000 \mathrm{~m}$.

The mine reports suggest that the average gas content in virgin areas is $\sim 13 \mathrm{~m}^{3} /$ tonne, which indicates an in situ gas pressure of approximately $2-3 \mathrm{MPa}$ from the $25^{\circ} \mathrm{C}$ adsorption isotherms of the coal seam \#8. It is also known that, due

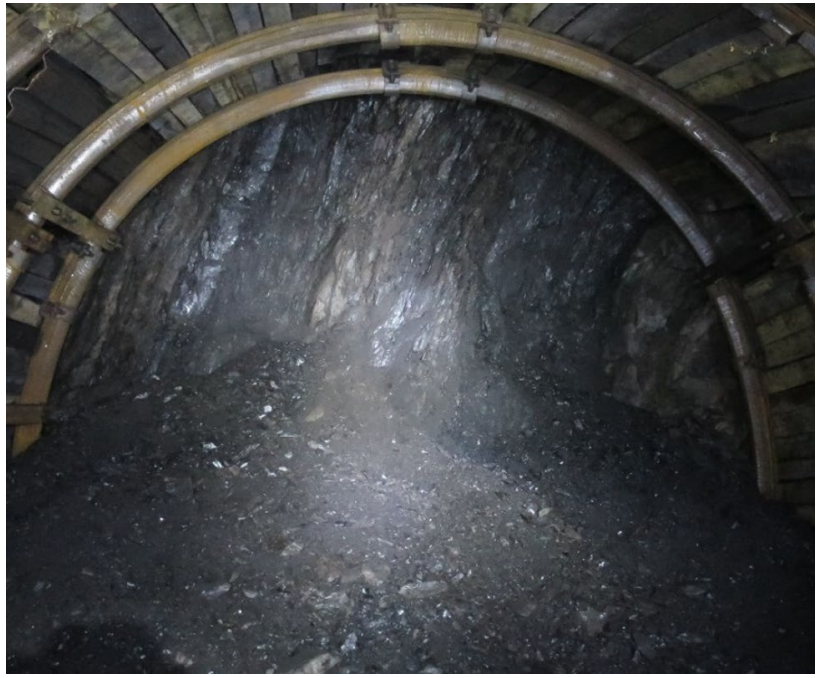

Fig. 3 Sublevel development heading in Seam \#8 illustrating the friable nature of the coal seam 
to high in situ horizontal stresses, the permeability of Seam \#8 is very low. The relatively soft coal, high in situ stresses, along with low permeability and high gas content, present a considerable risk for coal and gas outburst, particularly when driving the in-seam sublevel production headings.

To reduce methane emissions and coal and gas outburst risks, the mine is considering pre-drainage of the coal seam ahead of the sublevel development headings in advance. Therefore, the use of borehole slotting techniques reported in the literature were investigated for their effectiveness in stimulating the boreholes and achieving high drainage rates. As already experienced in previous trials, it has been rather difficult, if not impossible, to maintain the stability of long in-seam boreholes drilled from the development headings. As an alternative, it is proposed to drill the slotted boreholes from a nearby stone gallery in the footwall of \#8 Seam, parallel to the direction of maximum horizontal stress, and cutting through the coal seam along its thickness. The following sections describe the numerical simulation work carried to determine the key parameters that affect the performance of slotted gas drainage boreholes before a full-field implementation of the technique is undertaken.

\section{Numerical Modelling and Performance Assessment of Borehole Slotting Operations}

\subsection{Basic Theory}

The fundamental principles of borehole slotting operations are presented in Fig. 4. As can be seen, slots created along the borehole are expected to extend the size of stress relief zone induced by coal failure around the borehole. As a result, stress relief, fracture generation, and permeability enhancement inside the failure zone can effectively stimulate gas production. On the other hand, outside the failure zone, the abutment stress created results in a relatively small low permeability gas flow barrier, which can affect the nature of gas transport from the coal seam towards the borehole. The permeability contrast inside and outside the failure zone results in two unbalanced gas release time scales. Benefiting from the slotting stimulation, rapid gas release can be achieved within the failure zone, however, a longer lead time may be required to capture gas from outside the failure zone. Multiple slots in the same borehole and multiple
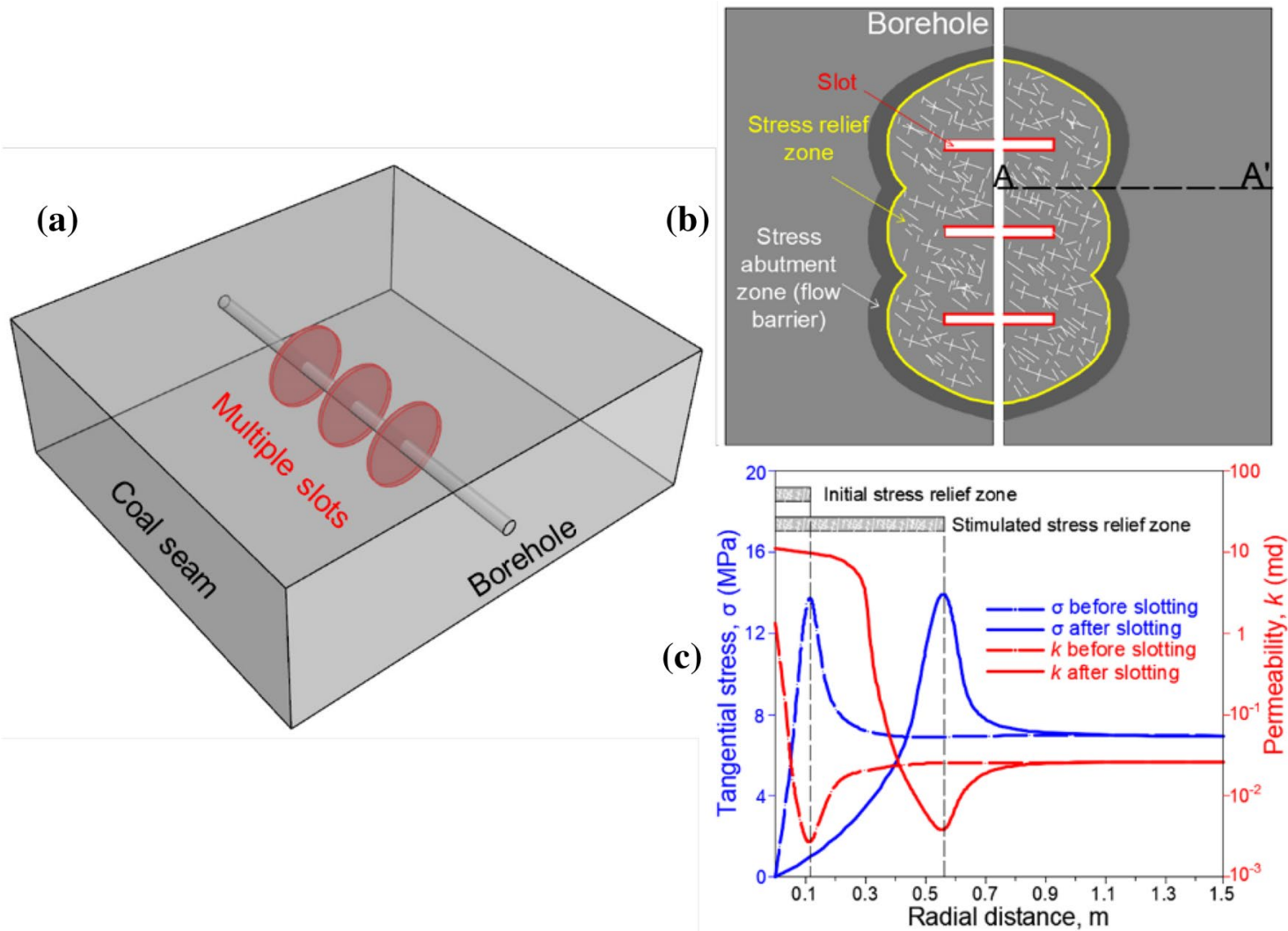

Fig. 4 Schematics showing the principals of borehole slotting operations: a a three-dimensional view of multiple slots in a horizontal borehole, b horizontal cross-section at the borehole level, and $\mathbf{c}$ stress and permeability profiles along $\mathrm{A}-\mathrm{A}^{\prime}$ before and after slotting 
slotted boreholes resulting in connecting stress relief zones can help overcome this problem.

For each slot, the effective stimulation zone is limited by the failure zone size created around it. An ideal stimulation design aims at maximising and seamlessly connecting stress relief zones induced by individual slots to achieve rapid and extensive gas release in the entire coal seam. In this research, the failure zone size (or the failure zone volume $V$ ) has been taken as the quantitative indicator to evaluate the performance of different slotting operations. The effect of varying stress conditions, coal properties, and slot geometry and spacing on the development of stress relief zone will all be discussed in detail in the numerical simulations described in the following sections.

Slots can be created through mechanical or hydraulic or a mixed approach. The most common method involves using high pressure waterjet to create circular/disc shape slots in pre-drilled gas drainage boreholes. The entire system normally includes a drilling bit, nozzle, water tank, highpressure pump and high-pressure hose. The pump can provide 30-40 MPa water through drilling pipe to the nozzle to create waterjet. The output water pressure from the pump can be also regulated. The nozzle can rotate along with the rotation of drilling bit, which eventually creates a circular slot. During the slotting process, a large amount of water carrying broken coal mass will be collected at the collar of the borehole. Please refer to Lin et al. (2015) for a more detailed description.

\subsection{Review Control Parameters Affecting Borehole Slotting Performance}

Based on the theory of slotting operations, slotting performance is most likely to be related with three aspects:

- Mechanical strength of coal, which includes cohesion, friction angle, residual cohesion, etc. These parameters control the strength of intact coal as well as residual strength of failed coal, which have a direct impact on the failure criteria and size of stress relief zone.

- In situ stress, which include the magnitude and orientation of principal stresses. The stress conditions may also contribute to the shape of failure zone and its propagation.

- Geometry of slots, which includes the diameter, width, aspect ratio, shapes of slots and spacing between multiple slots.

In this paper, the above-mentioned parameters will be investigated through a numerical approach and the importance of individual parameters in affecting borehole slotting performance will be assessed. Note that these parameters were selected not only because they are likely to be the first-order control parameters for slotting performance, but also their simplicity to be considered in numerical simulations. Due to the limitation of this paper's scope, other factors may also be potential control parameters, but not covered here are briefly summarised below, which are worth investigating in future studies.

- Natural discrete fracture network. The orientation of bedding planes and cleats, and how they are spatially correlated with the slot orientation. Their mechanical strength, spacing, persistence, and aperture of these natural fractures may have different impacts on slotting performance.

- Operation parameters to create slots. For hydraulic slotting, this includes pump output pressure, nozzle size, number of nozzles, waterjet impact angle on coal surface, rotation rate of drilling bits, etc.

- Fluid flow parameters. Since the ultimate goal of slotting operations is to enhance gas drainage performance, parameters control gas flow around slotted boreholes should be investigated building upon the geomechanical understanding presented in this paper. Potential flow parameters to be studied include gas content, gas pressure, permeability, relative permeability, water saturation, desorption, diffusion coefficient, etc.

\subsection{Development of the Baseline Scenario}

Numerical models to assess stress relief and the volume of failure zone around slotted boreholes were developed in FLAC $^{3 \mathrm{D}}$, an advanced geotechnical analysis software. The baseline scenario was developed based on the orientation of the planned drilling operations at the Montsacro Colliery. As shown in Fig. 5, the physical dimensions of the borehole slotting model are $10 \times 5 \times 10 \mathrm{~m}$ (length $\times$ width $\times$ height). The cylindrical zone at the centre of the model was refined to accommodate the simulated borehole and the slot. The entire model domain was assumed to be within Seam \#8 at a depth from -500 to $-510 \mathrm{~m}$.

The in situ stress conditions were assigned based on the reported stress field by the mine, where the maximum principal stress is horizontal and along the $y$-axis (parallel to the borehole and perpendicular to the strike of the coal seam as described earlier). The minimum principal stress is vertical and estimated by computing the overburden weight using an average rock density of $2360 \mathrm{~kg} / \mathrm{m}^{3}$. The boundary conditions of the model were such that it was laterally confined and fixed at the base.

In the model, only a $5 \mathrm{~m}$ long section of the borehole, with a diameter of $60 \mathrm{~mm}$, within the coal seam was simulated. To avoid potential overlap and interference between multiple slots and analyse the de-stressed failure zone around a single slot, only one slot was modelled first. A double-slot model was developed later as presented in Sect. 3.8 to understand 
Fig. 5 Model geometry and the central refined area for the slotted borehole model (the baseline scenario)

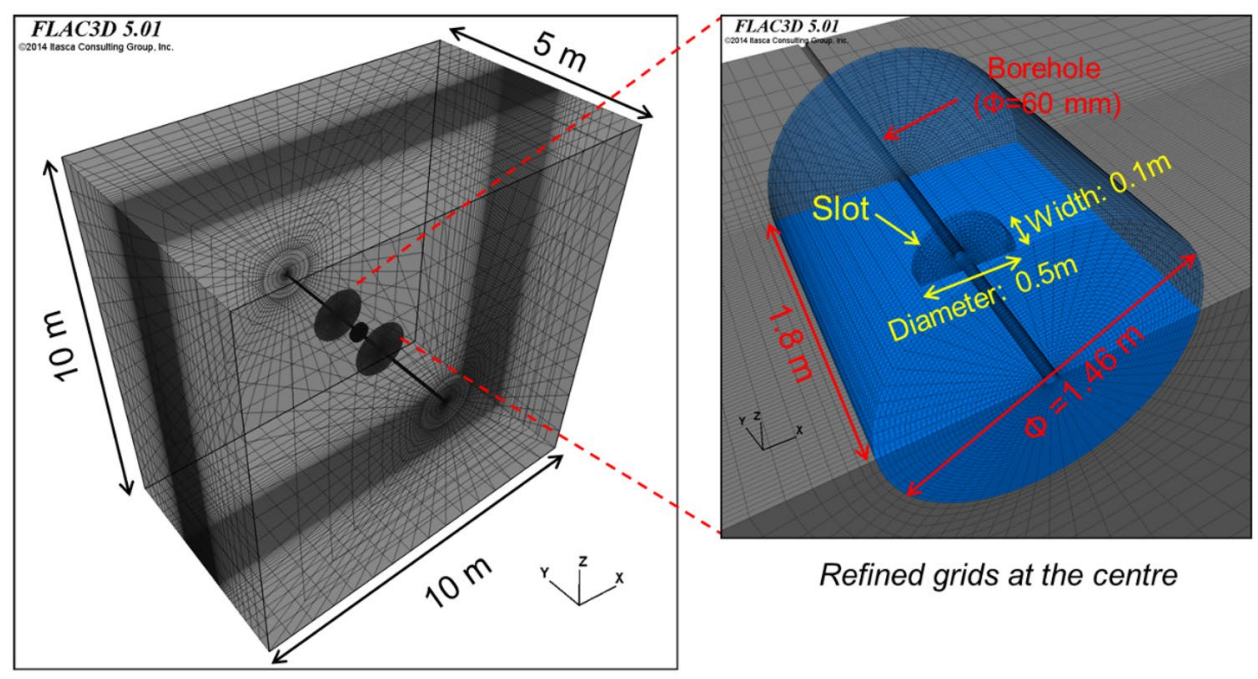

the effect of interference between multiple slots. In terms of the baseline slot geometry, a slot of $0.1 \mathrm{~m}$ wide (Lin et al. 2015) and $0.5 \mathrm{~m}$ diameter (Yang et al. 2016) was created at the centre of the refined area.

As summarised below, each simulation scenario consists of three steps: initial equilibrium, borehole drilling and slotting operations. This procedure is repeated and tailored accordingly for each simulation scenario in each sensitivity study:

1. The initial stress equilibrium is established first in the model.

2. Borehole drilling is then simulated in the model by assigning 'NULL' property (no mechanical stiffness and strength) to the grids representing the borehole. Solve the model to equilibrium before moving on to the next step.

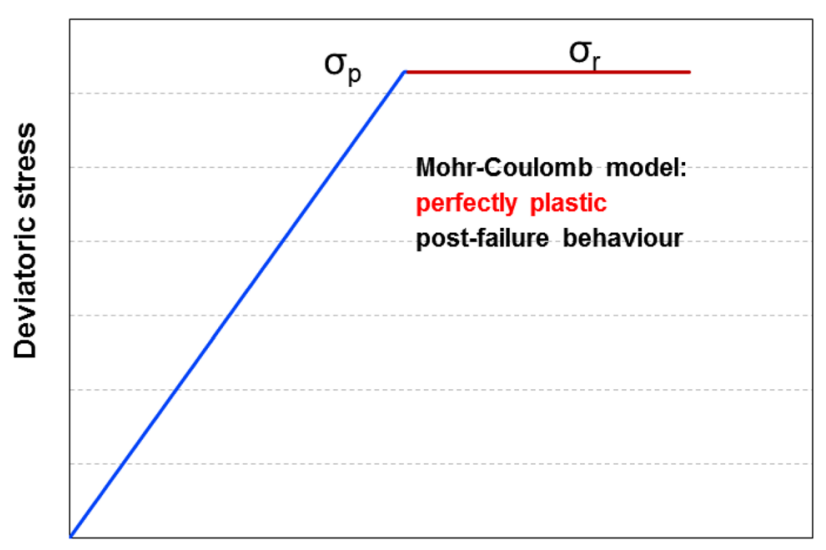

Axial strain

(a)
3. Based on the stress field generated after drilling, the grids representing the slot are assigned with 'NULL' property to simulate the slotting operation. Solve the model to equilibrium for analysis.

The constitutive model used in the simulation can largely affect the propagation of the failure zones created by slotting. The commonly applied Mohr-Coulomb (MC) model in FLAC ${ }^{3 \mathrm{D}}$ uses classic Mohr-Coulomb failure criterion to evaluate rock failure, in which the peak strength $\left(\sigma_{\mathrm{p}}\right)$ is controlled by cohesion $(C)$ and internal fraction angle $(\varphi)$ as illustrated in Fig. 6a. However, the MC constitutive model assumes a perfectly plastic behaviour after failure using constant cohesion and friction angle, which does not represent the weakening of coal/rock strength $\left(\sigma_{\mathrm{r}}\right)$ at the post-failure stage. This may result in an underestimation of the failure zone size around a borehole. While using Mohr-Coulomb

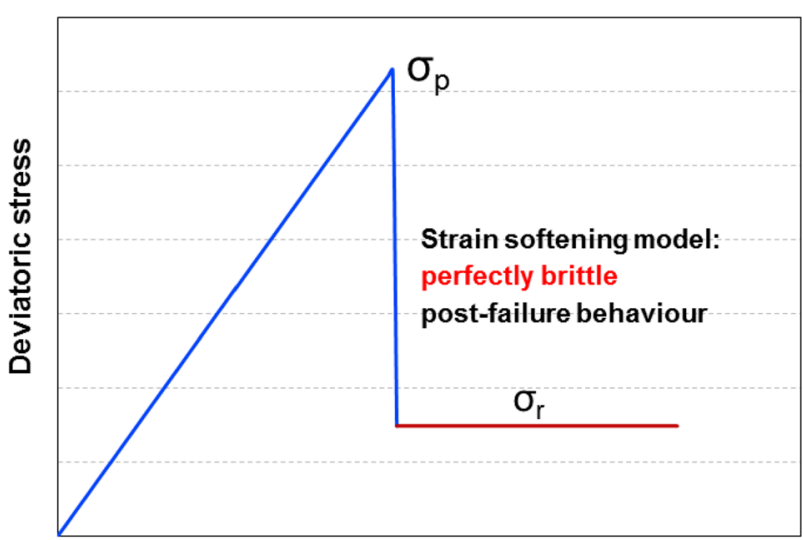

Axial strain

(b)

Fig. 6 Stress-strain behaviour of $\mathbf{a}$ the Mohr-Coulomb (MC) model and $\mathbf{b}$ the strain softening (SS) model 
failure criterion to detect failure, the strain softening (SS) model accounts for the weakening of rock in the post-failure stage by redefining cohesion, friction and dilation as piecewise-linear functions to inelastic strain. At each time step, the code measures the total plastic shear and tensile strains by changing the hardening/softening parameters. By doing this, SS model has the capability of simulating the cohesion, friction, dilation and tensile strength harden or soften after the onset of plastic yield.

Since the coal seam at Montsacro Colliery is known to be extremely brittle (see Fig. 3), the SS model was preferably used in the baseline scenario due to its advantage of better capturing the post-failure behaviour of coal. For comparison, both constitutive models were run as presented in this section. Rock mechanical properties used in these two constitutive models are summarised in Table 1. In the SS model, it was assumed that cohesion $(C)$ would be reduced to residual cohesion $\left(C_{\mathrm{r}}\right)$ when the plastic shear strain exceeds $\varepsilon_{\mathrm{p}}$. Note that all the parameters listed in Table 1 for the SS model were used as the baseline values for the scenarios to follow. The parameters listed in Table 1 were not lab measurement results, but assumed values made from a reasonable range for poor quality rock as suggested by Hoek and Brown (1997) and Hoek (2007). This is because the coal at
Montsacro Colliery is extremely brittle and a few attempts to core coal samples and test in the lab were not very successful. The uncertainty of these input parameters is one of the motivations to conduct a sensitivity analysis regarding geomechanical properties in Sect. 3.5.

The difference between the volume of failure zones obtained when using MC and SS models is demonstrated in Fig. 7. The failure zone created by drilling and slotting are shown in blue and red grids, respectively. The failure zone volume $(V)$ induced by slotting within the refined area was also calculated: the failure zone size estimated by the SS model is more than two times larger than that estimated by the MC model. It is clear that the MC model ignores postfailure weakening of the coal and underestimates the failure zone size around the borehole, and therefore, the actual slotting performance.

\subsection{Sensitivity of Slotting Performance to Grid Size}

Since this model involves simulating plasticity softening behaviour of coal, the selection of different grid sizes may affect model results. A high-resolution grid model can represent the slotting-induced stress distribution and failure zones

Table 1 Rock mechanical and strength properties of the coal seam at Montsacro Colliery

\begin{tabular}{llllllll}
\hline Model & $K(\mathrm{GPa})$ & $G(\mathrm{GPa})$ & $\varphi\left(^{\circ}\right)$ & $C(\mathrm{MPa})$ & $C_{\mathrm{r}}(\mathrm{MPa})$ & $\varepsilon_{\mathrm{p}}$ & $t(\mathrm{MPa})$ \\
\hline MC & 1.3 & 0.6 & 30 & 2.0 & - & - & -0.4 \\
SS & 1.3 & 0.6 & 30 & 2.0 & 0.6 & 0.001 & -0.4 \\
\hline
\end{tabular}

$K$ bulk modulus, $G$ shear modulus, $\varphi$ internal friction angle, $C$ cohesion, $C_{\mathrm{r}}$ residual cohesion, $\varepsilon_{\mathrm{p}}$ plastic shear strain limit, $t$ tensile strength cut-off

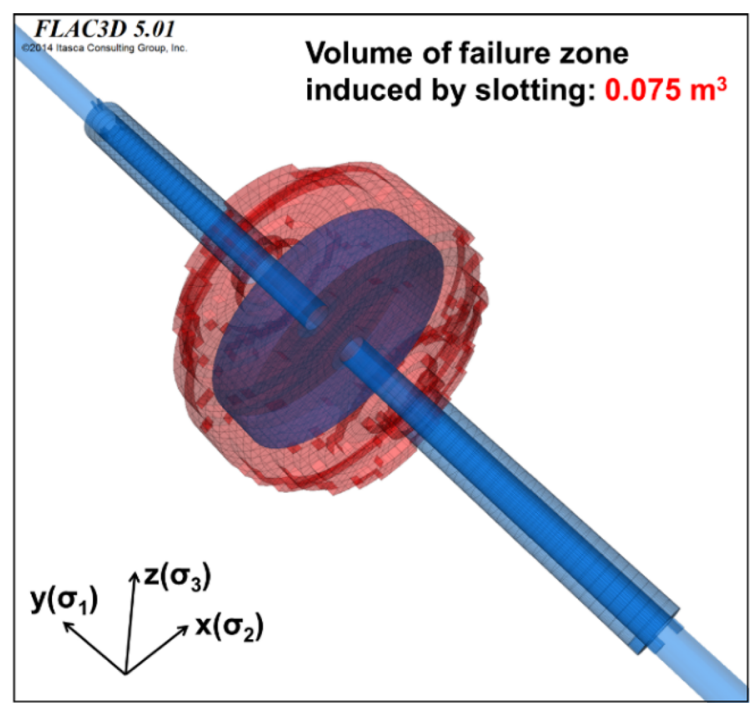

(a)

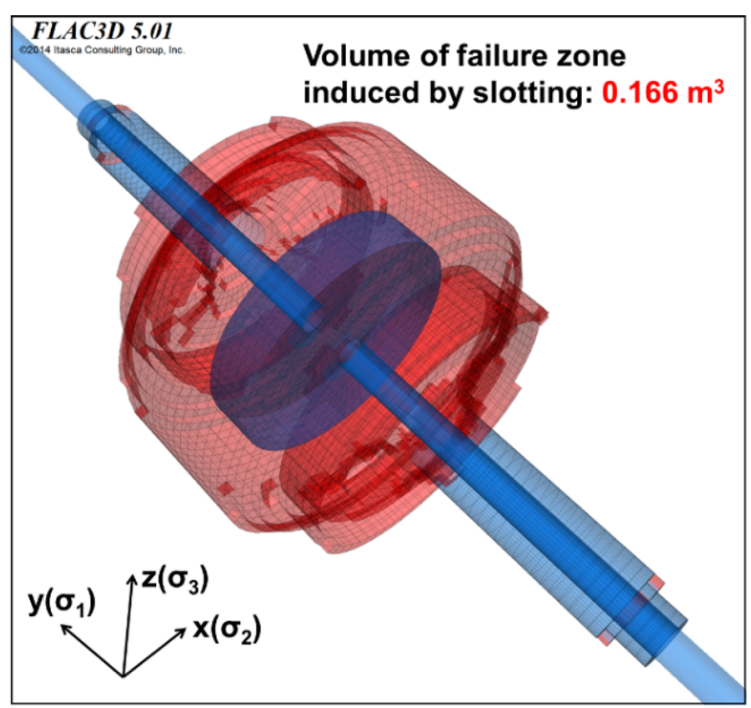

(b)

Fig. 7 Failure zone geometry using $\mathbf{a}$ the MC model and $\mathbf{b}$ the SS model for the baseline scenario 
as detailed as possible, however, this will inevitably increase the computational time required for reaching equilibrium.

To this end, building upon the baseline case developed in the previous section, a sensitivity study was conducted by varying the grid number within the refined zone from 28,000 to 168,000 (the grid number for the baseline case is $84,000)$. The failure zone induced by slotting was monitored for different degrees of refinement. It was found that, within the range considered, the impact of grid size on the geometry of failure zone is insignificant, as shown in Fig. 8. The volume of failure zones increases slightly with increasing number of refined grids, but the difference is rather small (less than $6 \%$ variation in all six scenarios). The baseline model with 84,000 grids was valid to represent the geomechanical behaviour properly without using large computational resources.

\subsection{Sensitivity of Slotting Performance to Geomechanical Properties}

\subsubsection{Peak Strength}

When using the Mohr-Coulomb failure criterion, cohesion $(C)$ and internal friction angle $(\varphi)$, which define the failure envelope, are the two most critical parameters affecting the performance of a slotting operation. The difficulties experienced in coring the extremely fragile coal sample in the laboratory meant that the rock mechanical properties of the coal seam at Montsacro Colliery could be highly variable.

Therefore, a wide range of $C$ and $\varphi$ values were used to assess the effect of these parameters on slotting-induced failure zone development (Fig. 9). The scenarios were run by changing the value of cohesion (or the friction angle) only, while keeping the other input parameters constant. In the study range investigated, the failure zone volume was found to be near-linearly affected by cohesion, however, the failure zone size was found to be extremely sensitive to the change of internal friction angle, and follow a negative power law relationship.

\subsubsection{Post-Failure Behaviour}

Although the SS model has the advantage of better representing coal failure behaviour, its application introduces two new input parameters, i.e., residual cohesion $\left(C_{\mathrm{r}}\right)$ and plastic shear strain $\left(\varepsilon_{\mathrm{p}}\right)$. The former determines the residual strength and the latter quantifies the brittleness of coal.

The sensitivity of slotting-induced failure zone size to the variation of these two parameters is presented in Fig. 10. The scenarios were run by changing the value of residual cohesion (or the plastic shear strain) only, while keeping the other input parameters constant. Increase of residual cohesion $\left(C_{\mathrm{r}}\right)$ from 10 to $50 \%$ of the initial cohesion $(C)$ results in a non-linear reduction of the failure zone size (see Fig. 10a). The failure zone volume and (a) Volume of failure zone induced bv slottina: $0.160 \mathrm{~m}^{3}$

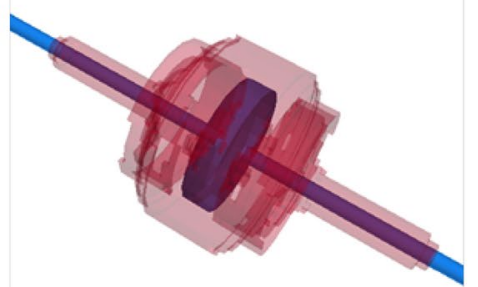

(d) Volume of failure zone induced by slotting: $0.167 \mathrm{~m}^{3}$

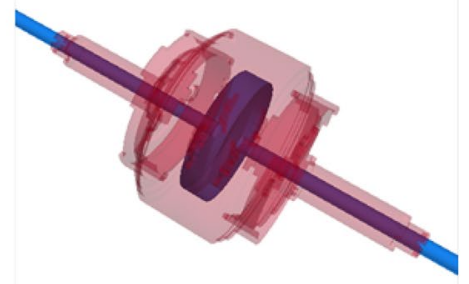

(b) Volume of failure zone induced by slotting: $0.163 \mathrm{~m}^{3}$

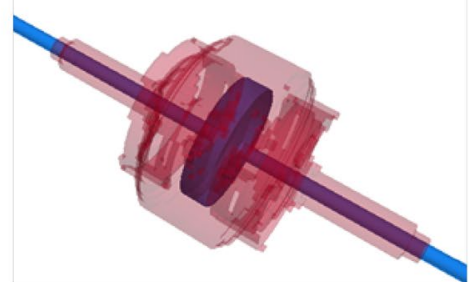

(e) Volume of failure zone induced by slotting: $0.168 \mathrm{~m}^{3}$

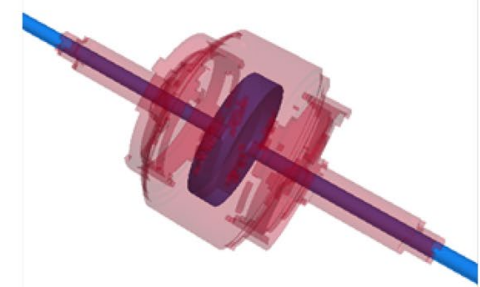

(c) Volume of failure zone induced by slotting: $0.166 \mathrm{~m}^{3}$

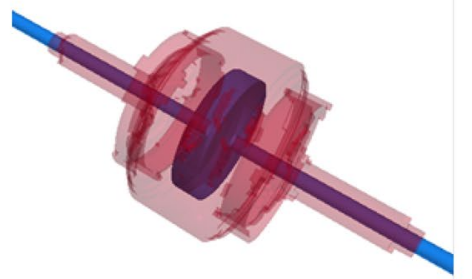

(f) Volume of failure zone induced by slotting: $0.169 \mathrm{~m}^{3}$

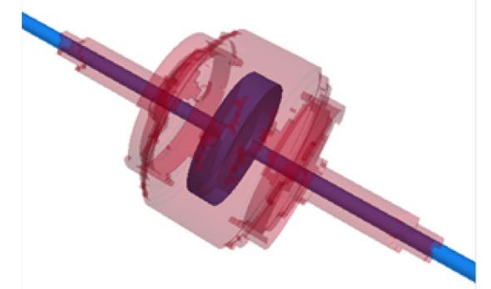

Fig. 8 Geometry of failed zones with different grid numbers within the refined zone: a 28,000, b 56,000, c 84,000-baseline case, d 112,000, e 140,000 , and $\mathbf{f} 168,000$ 


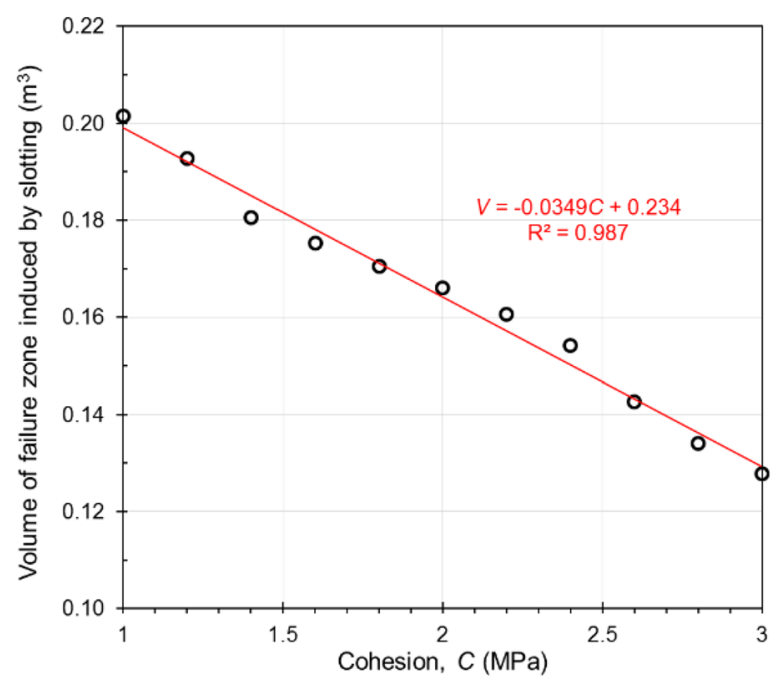

(a)

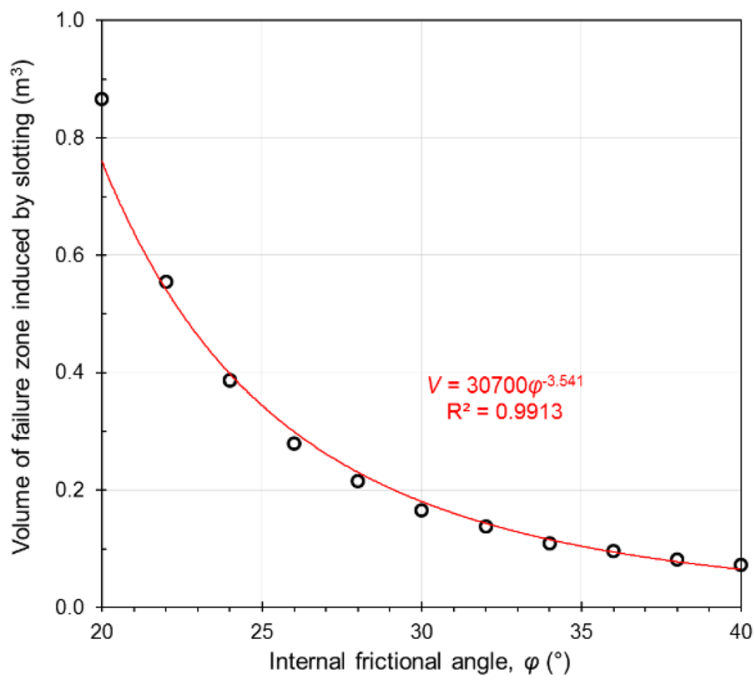

(b)

Fig. 9 The effect of varying a cohesion and $\mathbf{b}$ internal friction angle on the volume of failure zone induced by borehole slotting

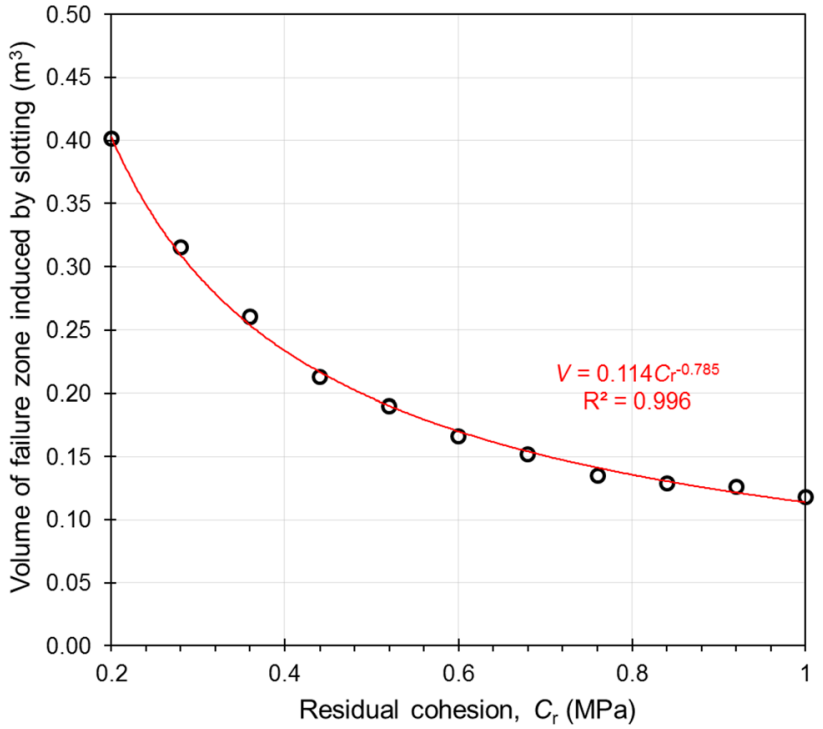

(a)

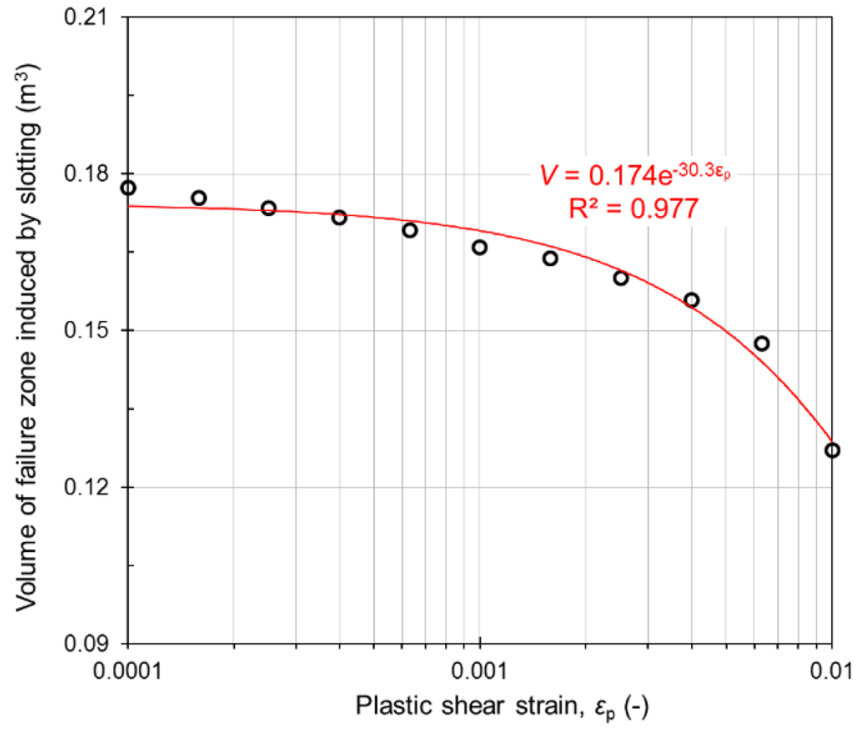

(b)

Fig. 10 The effect of varying a residual cohesion and $\mathbf{b}$ plastic shear strain on failure zone propagation in slotted boreholes

residual cohesion appear to follow a power law relationship, with the greater sensitivity found at the lower end of the residual cohesion range considered.

As Fig. 10b illustrates, as the value of plastic shear strain decreases, the volume of failed coal increases, however, this impact is fairly limited, especially in the low value range. An exponential function can be used to fit the relationship between plastic shear strain and the failure zone volume induced by slotting.

\subsection{Sensitivity of Slotting Performance to Stress State and Orientation}

\subsubsection{Stress Orientation with Respect to the Slot Plane}

The impact of varying the orientation of slot plane with respect to the orientation of principal stresses on the failure zone geometry and volume is presented in this section. If it is assumed that a slot plane can only be created perpendicular 
to a borehole, different drainage strategies would represent different in situ stress orientations with respect to the slot plane, which may affect the performance of a slotting operation. Therefore, based on the measured in situ stresses at Montsacro Colliery, the normal vector (n) of slots in the planned pre-drainage boreholes is parallel with the maximum principal stress $\left(\mathbf{n} / / \sigma_{1}\right)$. If considered in the long-term, slotting of in-seam horizontal boreholes or long downholes drilled from the development headings will have the normal vector parallel with $\sigma_{2}$ and $\sigma_{3}$, respectively. Note that, instead of rotating the borehole and slot plane, the relevant of in situ stresses orientations were rotated in the numerical models performed.

Figure $11 \mathrm{a}, \mathrm{b}$ show the shape and volume of the failure zone created by the slot with $\mathbf{n} / / \sigma_{2}$ and $\mathbf{n} / / \sigma_{3}$, respectively. Comparing these two scenarios with the findings of baseline scenario with $\mathbf{n} / / \sigma_{1}$ (see Fig. $7 b$ ), it can be concluded that, although the orientation of the slot plane only has marginal impact on failure zone volume, the shape of the failure zone for different cases can be significantly different. In the baseline scenario $\left(\mathbf{n} / / \sigma_{1}\right)$, the failure zone is close to a cylinder, while in the cases of $\mathbf{n} / / \sigma_{2}$ and $\mathbf{n} / / \sigma_{3}$, slotting operations results in an ellipsoidal failure zone. Note that the shorter axes in two ellipsoids are both in the orientation of the maximum principal stress $\left(\sigma_{1}\right)$. The presence of a much higher maximum principal stress forces the failure zone to propagate along the direction of lower principal stresses. These findings are extremely useful in designing the spacing of multiple slots in an individual borehole and the spacing of a number of boreholes with multiple slots.

\subsubsection{Stress Ratio}

In coal mining practice, it is not uncommon to place drainage boreholes into areas which have been disturbed by previous mining activities. Therefore, the stimulation performance of slotted boreholes may largely depend on the magnitude of the disturbed stress field. Furthermore, since the failure criterion is controlled by all three principal stresses, their magnitude relative to each other could also affect the shape and volume of the failure zone around slotted boreholes. Therefore, in this section, $\sigma_{3}$ was assumed to be constant at $12 \mathrm{MPa}$, but the ratio of $\sigma_{1}$ to $\sigma_{3}$ (denoted as $R_{13}$ ) and the ratio of $\sigma_{2}$ to $\sigma_{3}$ (denoted as $R_{23}$ ) were varied simultaneously to study their influence on the failure zone volume.

The stress range should not initiate faulting given using the baseline rock property. As suggested by Zoback (2010),

$R_{13}=\frac{\sigma_{3}}{\sigma_{1}} \leqslant\left(\sqrt{\mu^{2}+1}+\mu\right)^{2}$

where $\mu$ is the friction coefficient and, for the baseline scenario where $\varphi=30^{\circ}, \mu=\tan \varphi=0.577$. The equation above then yields $R_{13}=3$ as the maximum value which would not lead to faulting or fracturing all the coal elements. Allowing further for safety to ensure the stability of the model, a series of stress regimes defined by $1 \leq R_{23} \leq R_{13} \leq 2.8$ were modelled.

Model results of varying $R_{23}$ and $R_{13}$ simultaneously at three different stress orientations $\left(\mathbf{n} / / \sigma_{1}, \mathbf{n} / / \sigma_{2}\right.$, and $\left.\mathbf{n} / / \sigma_{3}\right)$

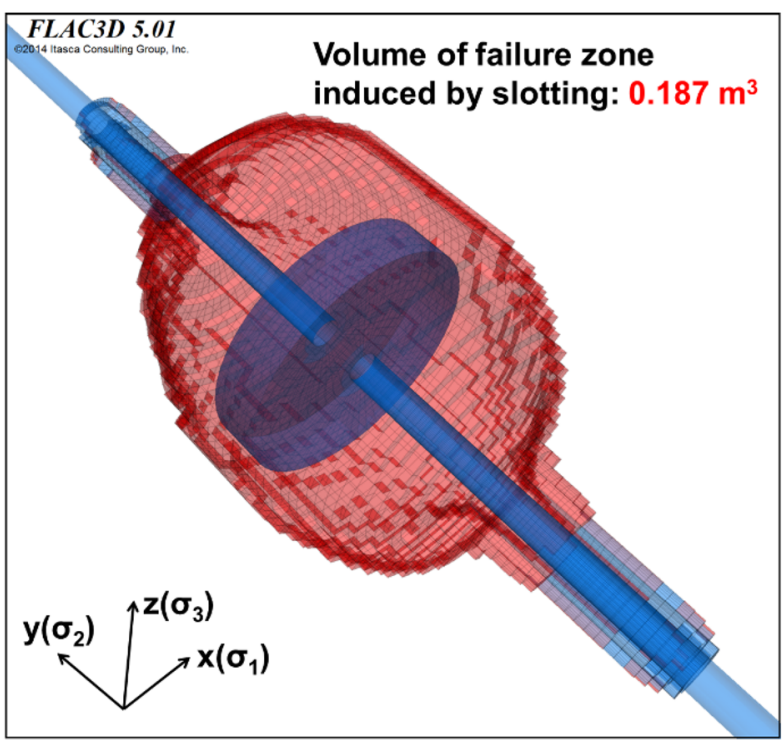

(a) Slot in Plan B: $\mathbf{n} / / \sigma_{2}$

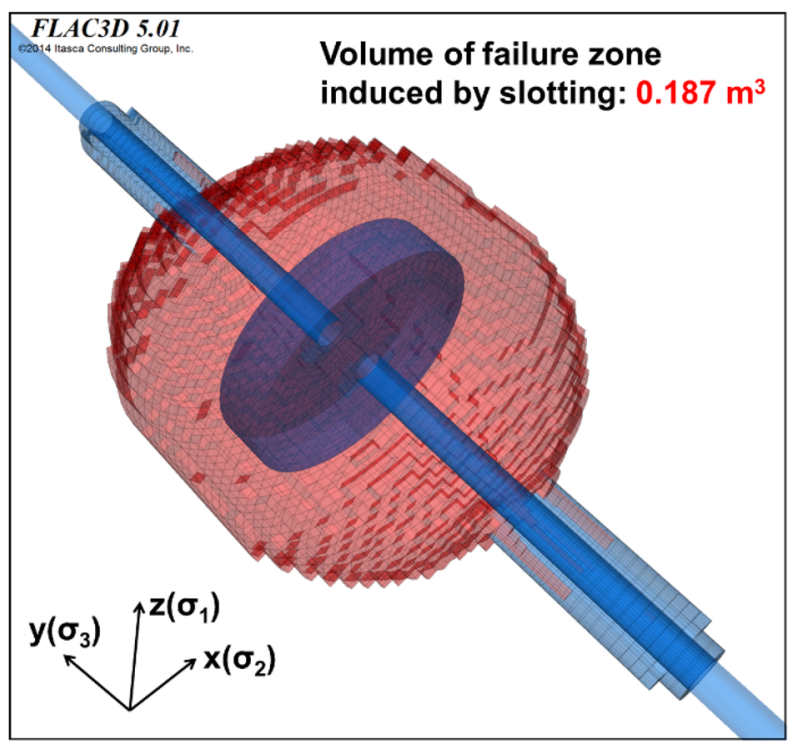

(b) Slot in Plan C: $\mathbf{n} / / \sigma_{3}$

Fig. 11 The effect of varying in situ stress orientation on failure zone geometry and volume 


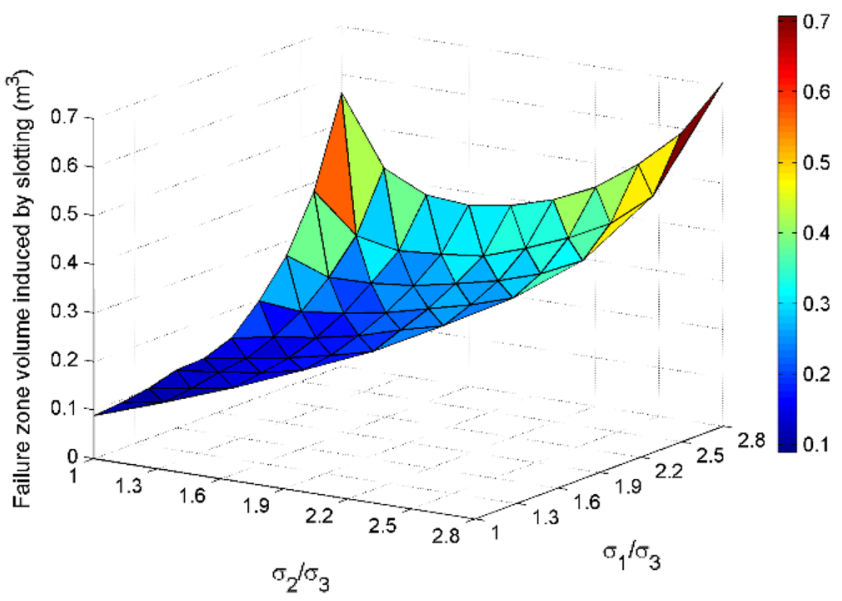

(a) $\mathbf{n} / / \sigma_{1}$

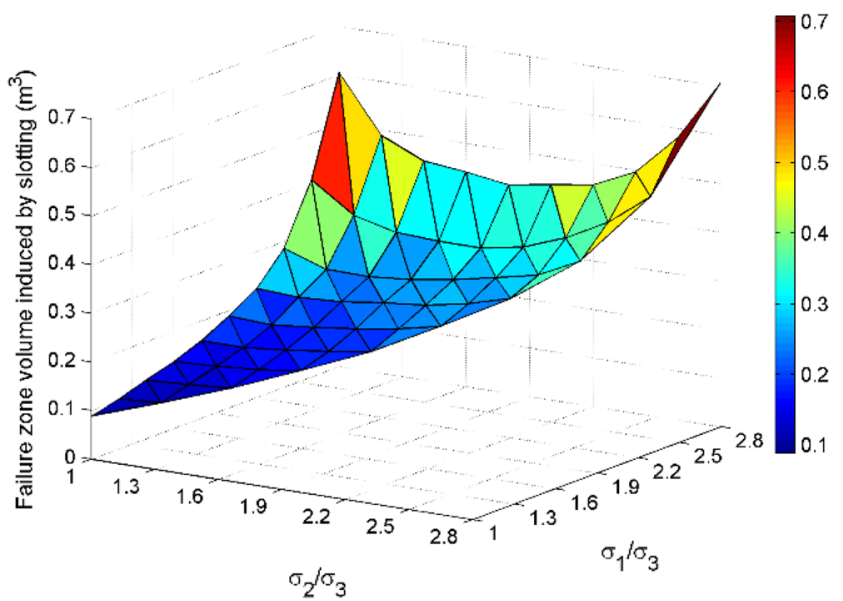

(b) $\mathbf{n} / / \sigma_{2}$

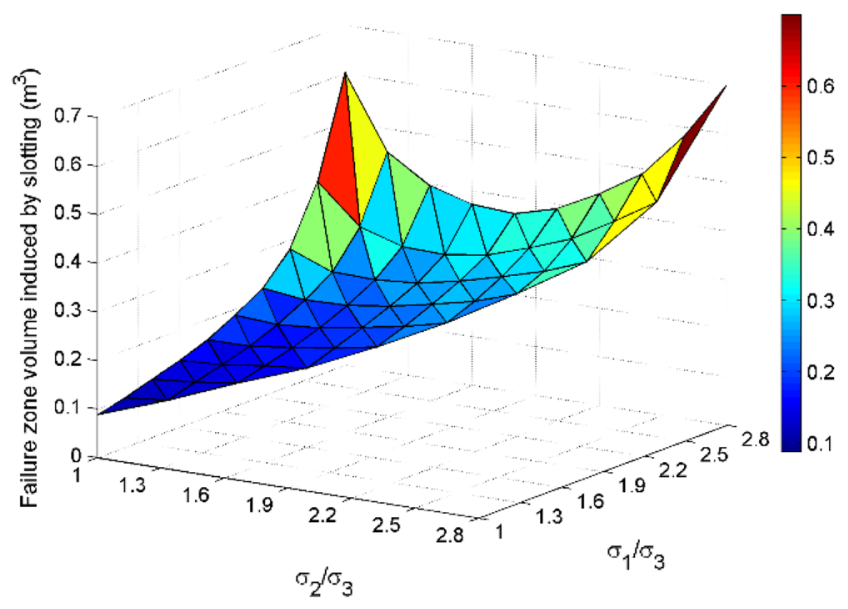

(c) $\mathbf{n} / / \sigma_{3}$

Fig. 12 The effect of varying stress ratio on failure zone volume

are plotted as surface contours in Fig. 12. The shape of the surfaces for all three stress conditions are similar. The significance of increasing the maximum principal stress can be clearly observed. Again, the relationship between $R_{13}$ and the failure zone volume is non-linear. As expected, the effect of increasing $R_{13}$ on failure zone volume is not independent from the level of intermediate principal stress $\left(R_{23}\right)$.

Note that the response of failure zone volume to the increase in intermediate principal stress is not always monotonic. When $R_{13}$ is low, an increase in $R_{23}$ also increases the failure zone volume. With a relatively high $R_{13}$, a larger failure zone can be achieved if $\sigma_{2}$ is either closer to $\sigma_{1}$ or $\sigma_{3}$.

\subsection{The Relationship Between Slot Geometry and the Volume of Failure Zone}

\subsubsection{Slot Diameter and Width}

Maintaining the borehole orientation and the strength properties of coal used in the baseline scenario, the effect of slot diameter and width on the failure zone size was investigated by varying the slot diameter from 0.3 to $0.7 \mathrm{~m}$ and the slot width from 0.02 to $0.20 \mathrm{~m}$, respectively. Model results obtained by varying these two parameters independently are shown in Fig. 13. The failure zone volume follows a binomial relationship with the slot diameter. On the other hand, the relationship between the slot width 


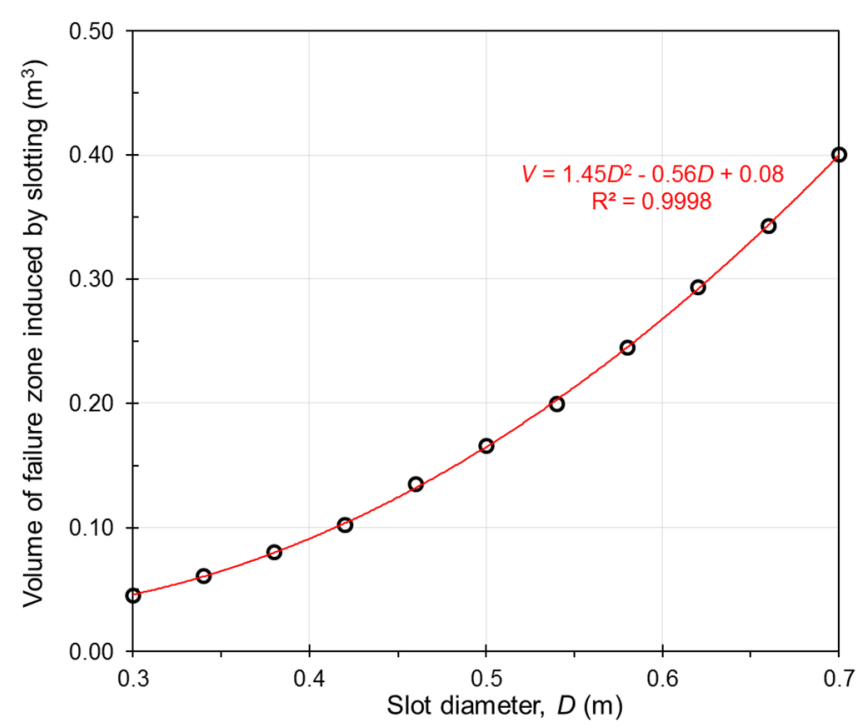

(a)

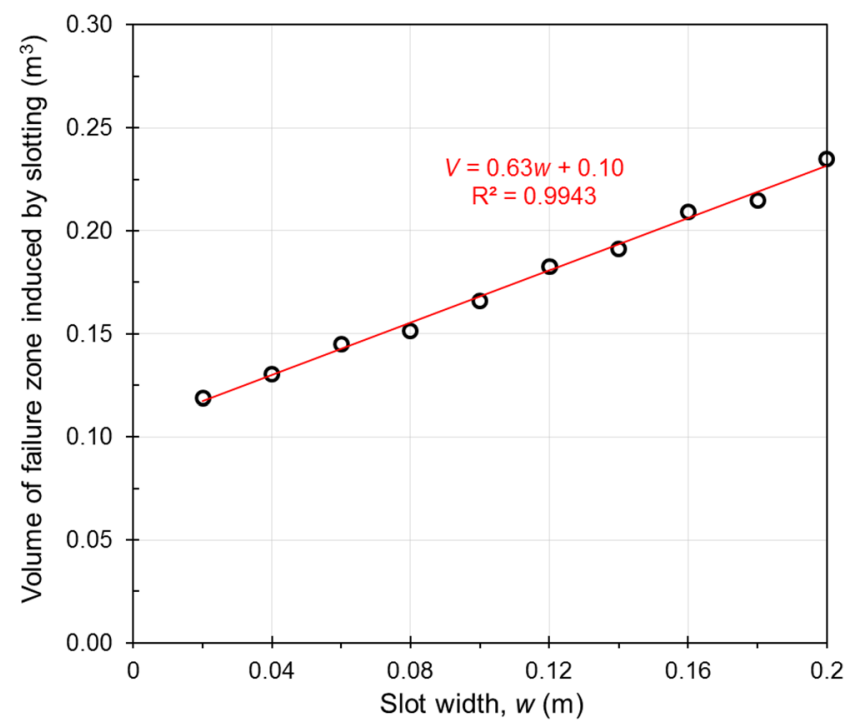

(b)

Fig. 13 The effect of varying a slot diameter and $\mathbf{b}$ slot width on failure zone volume

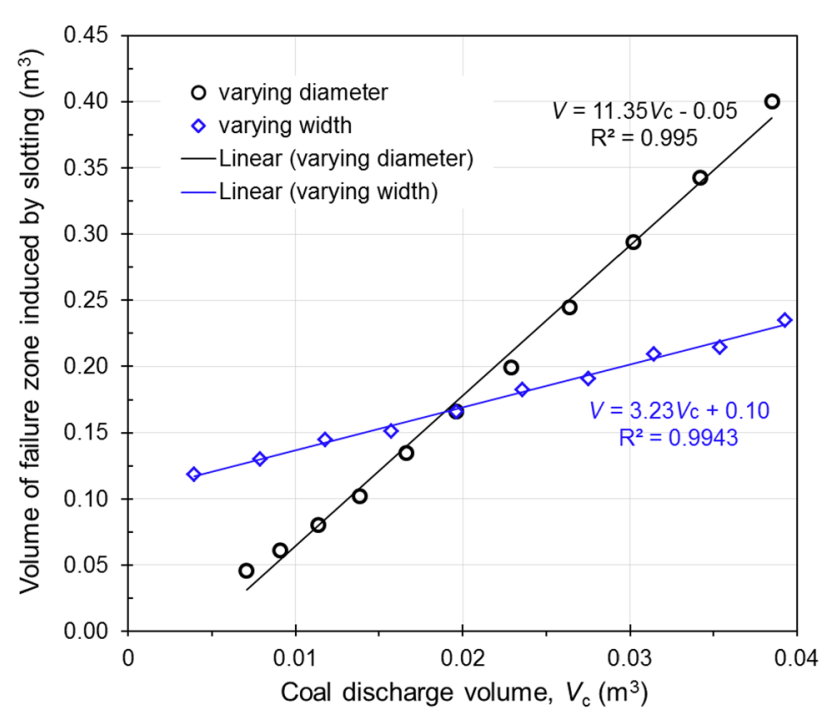

Fig. 14 The relationship between failure zone volume and coal discharge volume

and the failure zone volume is linear. This suggests that the volume of coal discharged $\left(V_{c}\right)$, i.e., the volume of slotted space, probably has a direct impact on the volume of failure zone induced by slotting, which is illustrated in Fig. 14. An increase in the coal discharge volume achieved by either varying the slot diameter or width can both increase the failure zone volume. However, as the figure suggests, increasing the slot diameter would be more effective in creating a much larger failure zone size.

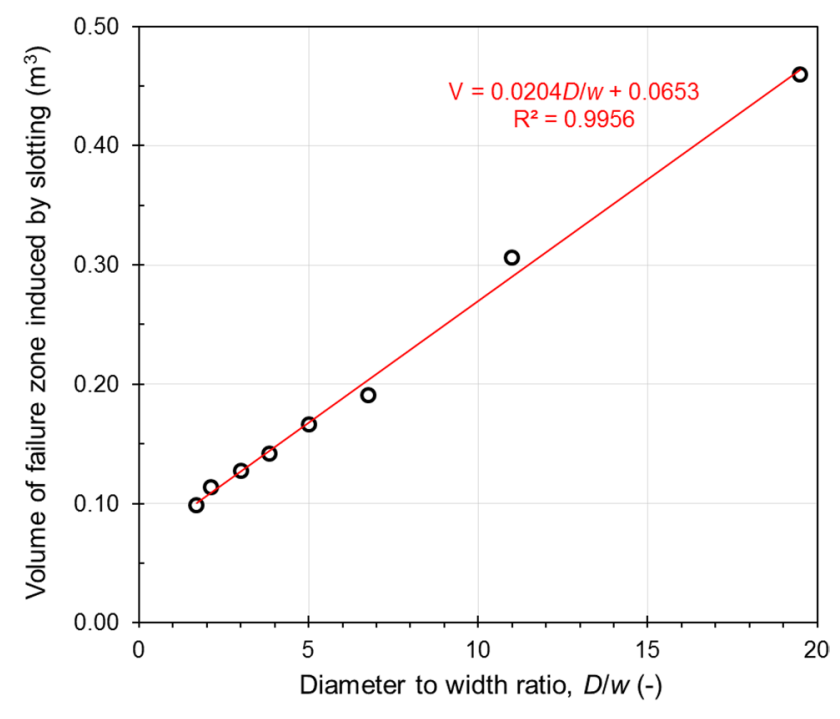

Fig. 15 The effect of varying the $D / w$ ratio on failure zone volume

Model results presented in Fig. 14 also raises a new question that, for the same coal discharge volume, different slot diameter to width ratios $(D / w)$ may also change the failure zone volume obtained. To confirm this hypothesis, eight new simulations were run using a fixed coal discharge volume $\left(0.02 \mathrm{~m}^{3}\right.$ as obtained by the baseline scenario), but different $D / w$ ratios. As shown in Fig. 15, the failure zone volume follows a linear relationship with the $D / w$ ratio.

Failure zone profiles in the vertical and horizontal planes cutting through the borehole for different $D / w$ ratios of 2.1, 5.0, 11.0, and 19.5 are presented in Fig. 16. A larger 
Fig. 16 Failure zone profiles in the a vertical and $\mathbf{b}$ horizontal planes cutting across the borehole

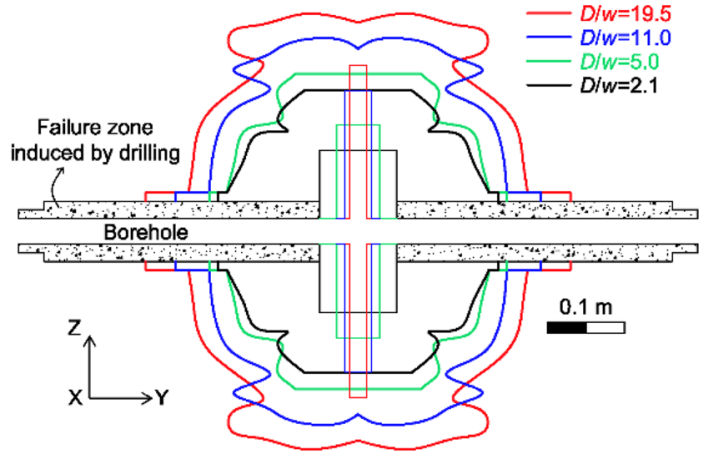

(a)

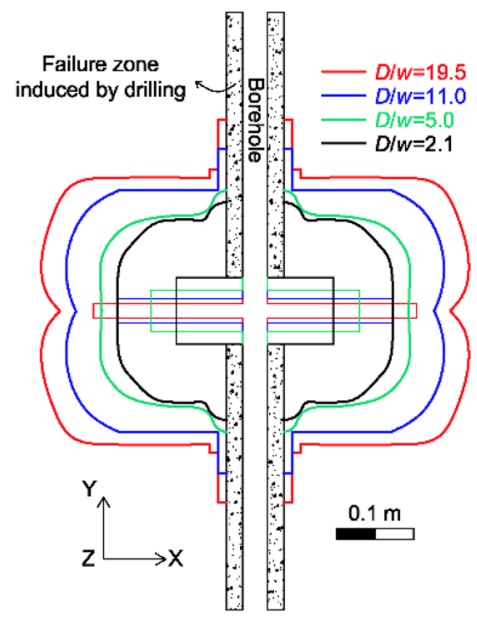

(b) diameter slot has the advantage of penetrating deeper into the coal seam, which creates a larger surface area and allow the coal along the two sides of the slot to release stress. It is believed that the large volume of stress relieved coal within the area 'shadowed' by the slot disc contributes the most to the stimulation of gas drainage performance. Therefore, in field practice, it is recommended to aim at creating 'long and thin' rather than 'short and thick' slots to maximise the stimulation impact.

\subsubsection{Elliptical Slot}

During slotting operations in the field, it is rather difficult to control the shape of slots accurately and, sometimes, the slot created may not be circular but elliptical. This can be caused by the heterogeneity of coal or uneven waterjet pressure loading on borehole wall. Theoretically, elliptical slots can also be achieved by controlling pump pressure and the orientation of waterjet, i.e., apply higher water pressure along the maximum principal stress direction and gradually reduce the pressure while waterjet rotating towards the minimum principal stress direction. An elliptical slot with long axis parallel to $\sigma_{1}$ can be created, but this requires high quality engineering control and can be challenging.

The performance of an elliptical slot would depend on the aspect ratio of long axis $(a)$ to short axis $(b)$, as well as the orientation of the long axis with respect to the orientation of principal stresses. To avoid the effect of the changes in coal discharge volume on the results as the $a / b$ ratio is varied, the area of each elliptical slot was fixed to be same as the area of the circular disk in the baseline circular scenario. Note also that, to accommodate the model scenarios with relatively large aspect ratios, the diameter of the central refined zone was extended from 1.46 to $2.86 \mathrm{~m}$ (please refer to Fig. 5 for the original refined zone size).

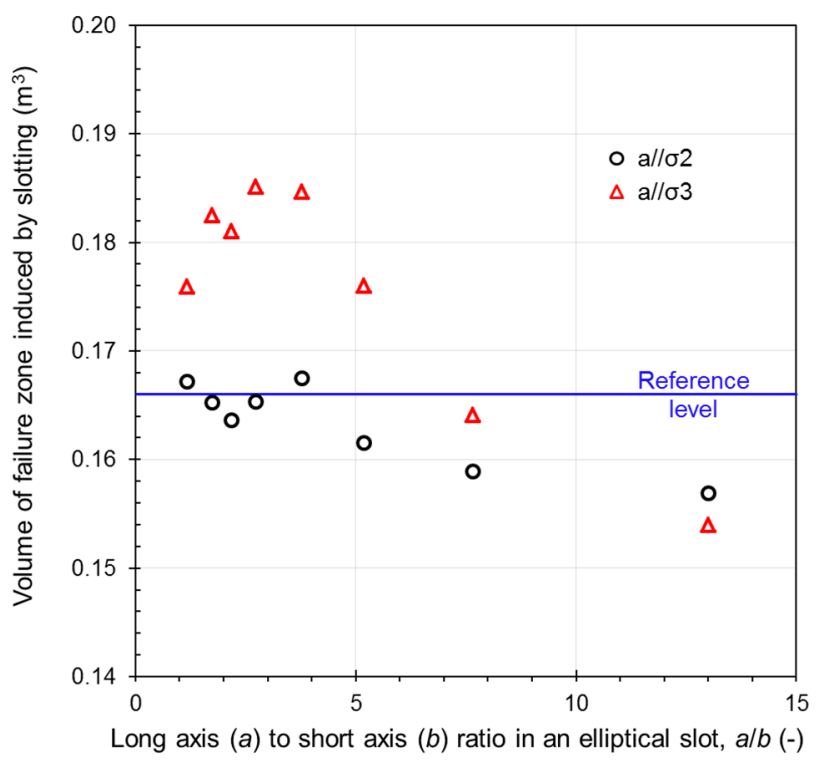

Fig. 17 The effect of varying the $a / b$ ratio in an elliptical slot on failure zone volume

Figure 17 shows the changes in failure zone volume with respect to the change in the $a / b$ ratio in an elliptical slot. The reference level indicates the failure zone volume induced by the baseline circular slot. In the case of $a / / \sigma_{2}$, the effect of varying $a / b$ ratio on the failure zone volume is fairly limited. On the other hand, for $a / / \sigma_{3}$, the elliptical slot results in approximately $12 \%$ increase in the failure zone volume when $a / b$ ratio is less than 5 . Both cases show a declining trend in the failure zone volume at high $a / b$ ratios.

Examining Fig. 17, one can infer that the angle between the long axis and principal stresses affects the failure zone volume around a slotted borehole. This relationship has been further investigated in Fig. 18, where the angle between $a$ 


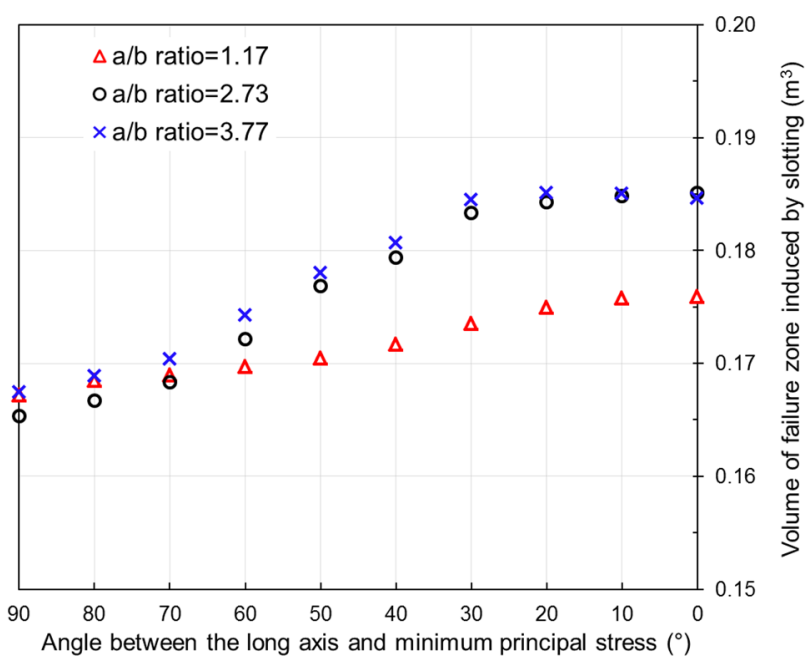

Fig. 18 The effect of varying the angle between $a$ and $\sigma_{3}$ on failure zone volume

and $\sigma_{3}$ is varied from $90^{\circ}$ to $0^{\circ}$ in three cases with low $a / b$ ratios. The figure illustrates that, as the long axis approaches the direction of minimum principal stress, the failure zone volume increases gradually and reaches its maximum when $a / / \sigma_{3}$. Note that the model results are also consistent with the findings proposed by Papanastasiou (2000): the elliptical holes with long axis parallel to the minimum principal stress are less stable. This conclusion is contradictory to the suggestions of classic elastic stress analysis, which is explained by the implementation of strain-softening material modelling in this study and Papanastasiou (2000).

\subsection{The Effect of Slot Spacing on Overall Performance}

Another critical question to be addressed is the design and optimisation of slot spacing along a borehole to minimise the number of slots cut, while maximising the size of the failure zone along each borehole. Since it is primarily the in situ stress conditions which determine the failure zone shape, the findings of previous modelling scenarios for a single slot were reviewed and the shape of failure zones induced were examined to obtain a first order approximation of optimum slot spacing.

As illustrated in Fig. 19a, the outer surface of the failure zone induced by a single slot was projected onto the slot plane along the borehole direction. The contours in the projection plane indicate the distance from each projection point to the failure zone outline. Figure 19b-d show the projection contours of the slot when its normal vector is parallel with the maximum, intermediate, and minimum principal stresses, respectively. Note that grids within $0.07 \mathrm{~m}$ from the borehole centre-line were not used for the projection plot due to the noisy data associated with the interference from drilling the borehole.

One main conclusion that can be drawn from Fig. 19 is that, the maximum extent of the failure zone is $0.5 \mathrm{~m}$ in all three in situ stress scenarios. This suggests that the spacing between two slots should be less than $1.0 \mathrm{~m}$ to prevent the failure zones created from overlapping and to achieve and effective stimulation along the borehole. Furthermore, as the mean value of the failure zone extension $\left(L_{\mathrm{m}}\right)$ in the baseline scenario was smaller than that achieved in the other stress orientation scenarios, denser slots may be required when $\mathbf{n} / / \sigma_{1}$.

Slot spacing design was further investigated by simulating multiple slots, where the interaction between two neighbouring slots can be analysed. The central refined zone of the model was extended from 1.8 to $3.6 \mathrm{~m}$ along $y$-axis (please refer to Fig. 5 for the original refined zone size) to be able to cover the full extent of failure zones induced by two slots. As before, the volume of failure zone induced by two neighbouring slots were recorded as the quantitative measure to assess each scenario. At the same time, the failure zone volume induced by a single slot in the scenarios described earlier were mathematically doubled (blue lines in Fig. 20) and used to compare these with the model results obtained for twin slots.

Slot spacings ranging from 0.1 to $1.3 \mathrm{~m}$ were modelled in all three principal stress orientations. These results are presented in Fig. 20. As the figures demonstrate, multiple slots spaced too closely underperform significantly. With the increase of slot spacing, the failure zone volume gradually increases and exceeds the single slot based approximation, reaching its maximum when slot spacing is approximately twice the mean value of failure zone extension $\left(s=2 L_{\mathrm{m}}\right)$. In the case of $\mathbf{n} / / \sigma_{1}$ scenario, any further increase in slot spacing results in a much reduced failure zone volume.

Different failure zone volume responses observed for each scenario as the slot spacing increased beyond $s=2 L_{\mathrm{m}}$ can be attributed to the stress conditions at the bridging area between two slots. As mentioned in Sect. 3.5.1, borehole slotting relaxes the coal and the most significant stress relief occurs in the direction perpendicular to the slot plane, i.e., along the direction of the borehole.

If it is assumed that, in the bridging area, there is one coal block under critical stress condition before failure. Any further reduction in $\sigma_{1}$ (in the baseline scenario $\mathbf{n} / / \sigma_{1}$ ) makes the coal block more stable as it moves closer to hydrostatic stress conditions (see Fig. 21). This explains why, in the case of $\mathbf{n} / / \sigma_{1}$, the interaction between two slots reduced the volume of failure zone significantly shortly after the $s=2 L_{\mathrm{m}}$ point was reached (Fig. 20 a). On the other hand, reduction in $\sigma_{3}$ (in the case of $\mathbf{n} / / \sigma_{3}$ ) increases the deviatoric stress $\left(\sigma_{1}-\sigma_{3}\right)$ and yields more failure, as illustrated in Fig. 20c, where a larger extra volume of failure zone and wider range 


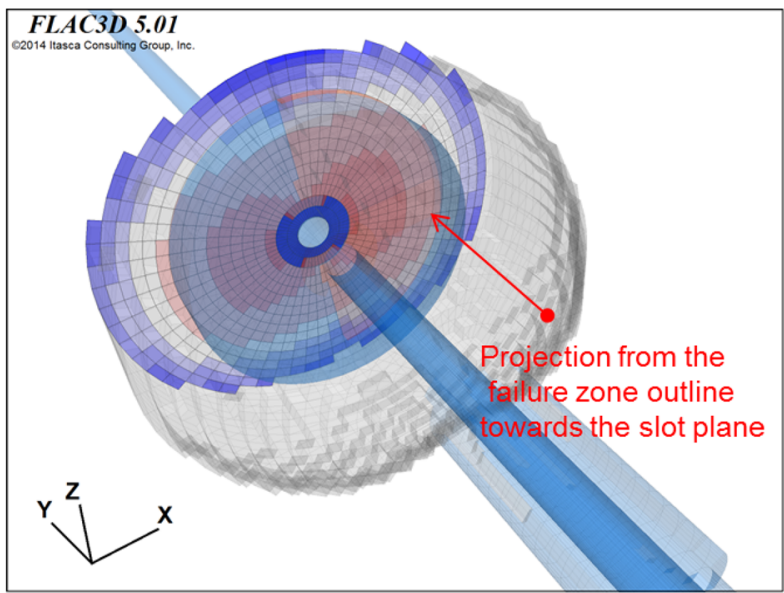

(a) illustration of the projection methodology followed

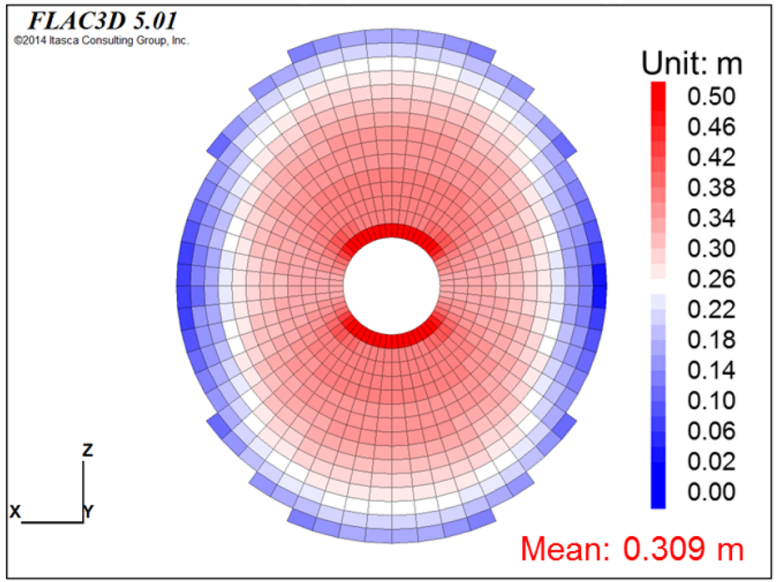

(c) $\mathbf{n} / / \sigma_{2}$

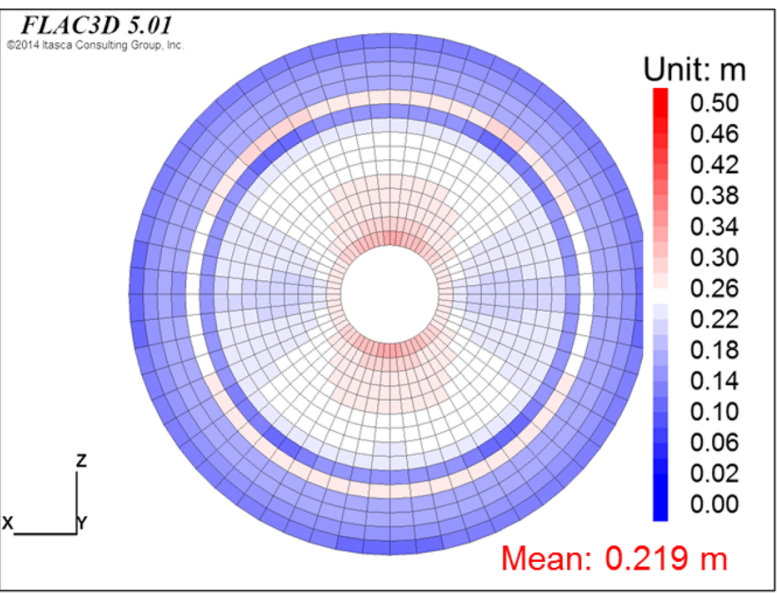

(b) $\mathbf{n} / / \sigma_{1}$

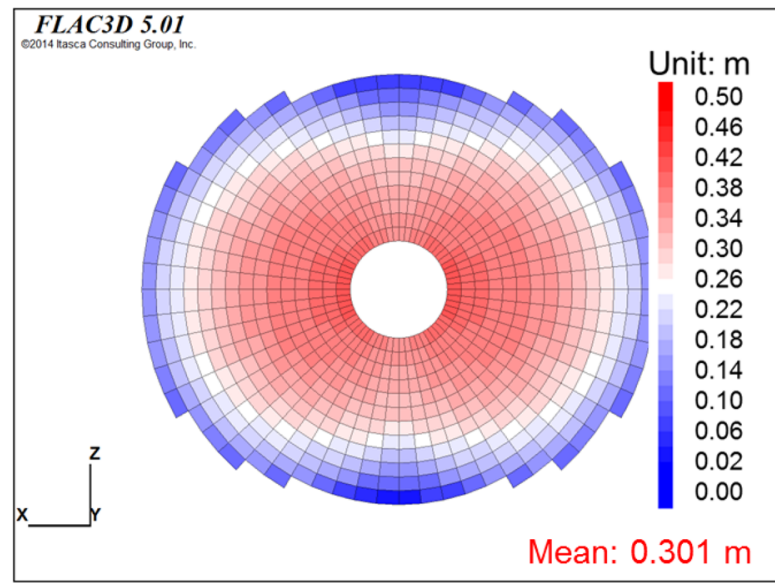

(d) $\mathbf{n} / / \sigma_{3}$

Fig. 19 Projection contours of the failure zone extension along the direction of the borehole

of optimal slot spacing is observed. The intermediate case $\left(\mathbf{n} / / \sigma_{2}\right)$ falls between these two extremes, yet it is more like the $\mathbf{n} / / \sigma_{3}$ scenario, since stress in the direction borehole may drop significantly and act as the new minimum principal stress. Therefore, whether multiple slotting provides as extra 'bonus' or a 'penalty' to the failure zone development depends on the prevailing stress along the borehole direction, perpendicular to the slot plane.

\section{Results and Discussion}

Based on systematic numerical modelling results for a single circular slot, the key parameters identified and their role in affecting the stimulation performance of slotted boreholes have been summarised in Table 2 . The sensitivity of the slotting performance to the key parameters used in the analysis of failure zone development is presented in the Tornado chart (Fig. 22), which shows $\pm 20 \%$ variation of each parameter from the baseline scenario. Surprisingly, internal friction angle $(\varphi)$ ranks as the most sensitive parameter in affecting slotting performance: $20 \%$ decrease in the internal friction angle can double the failure zone size. Slot diameter $(D)$ and the ratio of maximum principal stress to minimum principal stress $\left(R_{13}\right)$ are found to be the second and third influential parameters affecting slotting performance. These top three key parameters were summarised in Table 3.

The significant effect of internal friction angle is illustrated in Fig. 23, which scatters the stress states of 6000 randomly sampled grid elements from the central refined zone in the baseline scenario. The failure envelopes for baseline scenario, 20\% $C$ reduction, and $20 \% \varphi$ reduction are also plotted. As shown in this figure, the majority of elements (green dots) are intact coal and resting close to the in situ stress condition. Stress states in line with the residual strength envelop (red dots) represent the elements of failed coal, which have violated the failure criterion before, and are in residual condition now. 


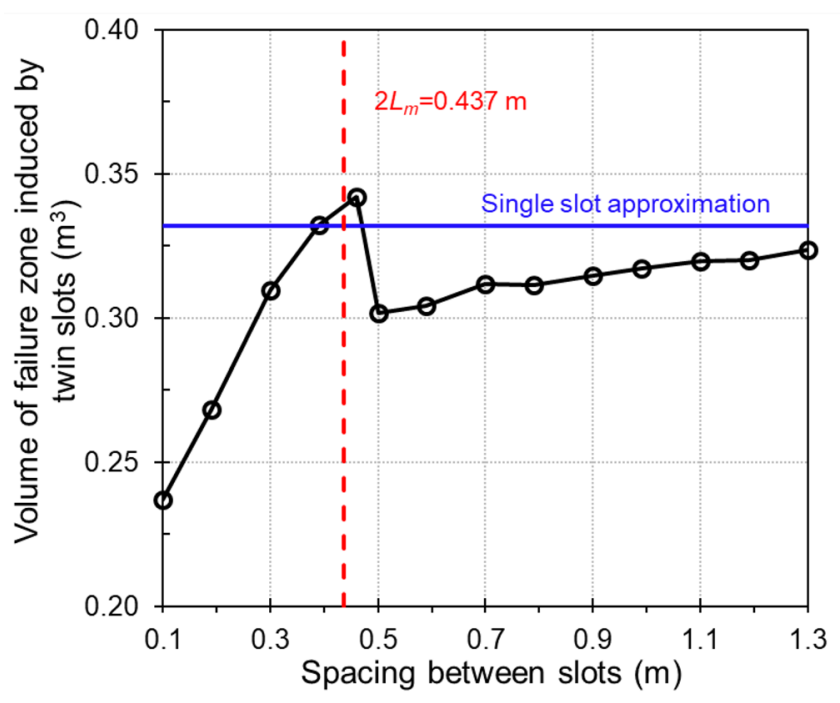

(a) $\mathbf{n} / / \sigma_{1}$

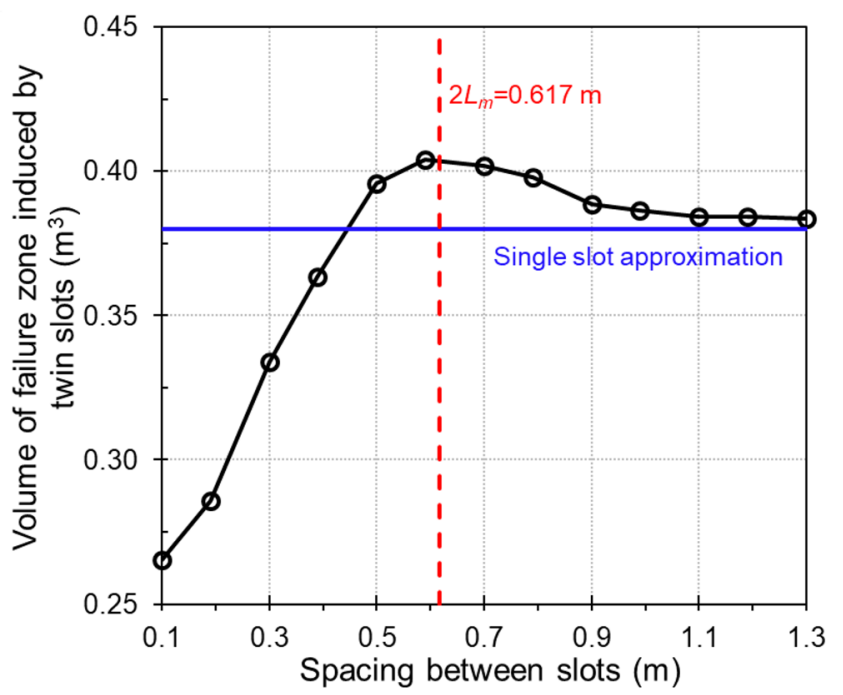

(b) $\mathbf{n} / / \sigma_{2}$

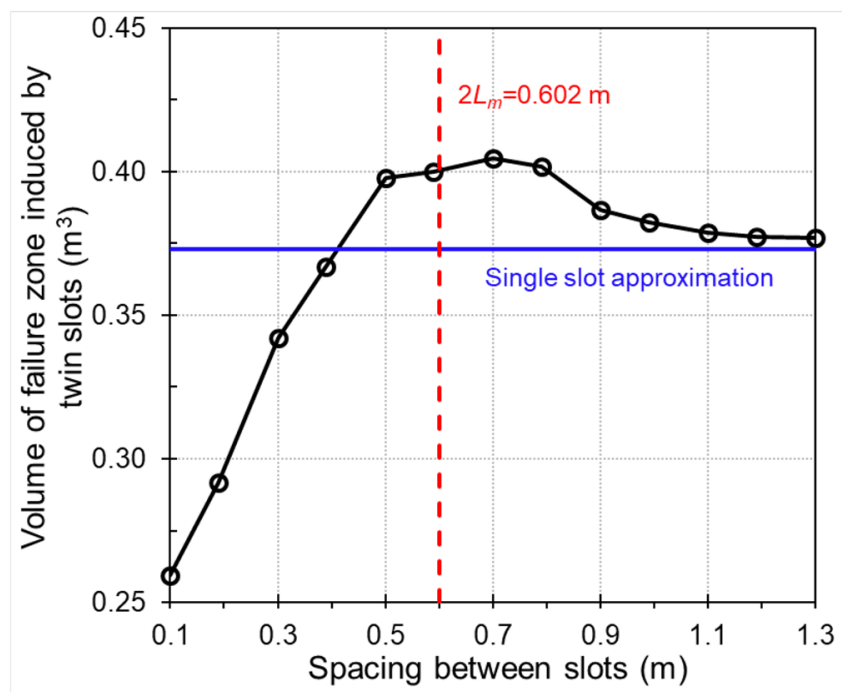

(c) $\mathbf{n} / / \sigma_{3}$

Fig. 20 The effect of varying slot spacing on failure zone volume at different principal stress conditions

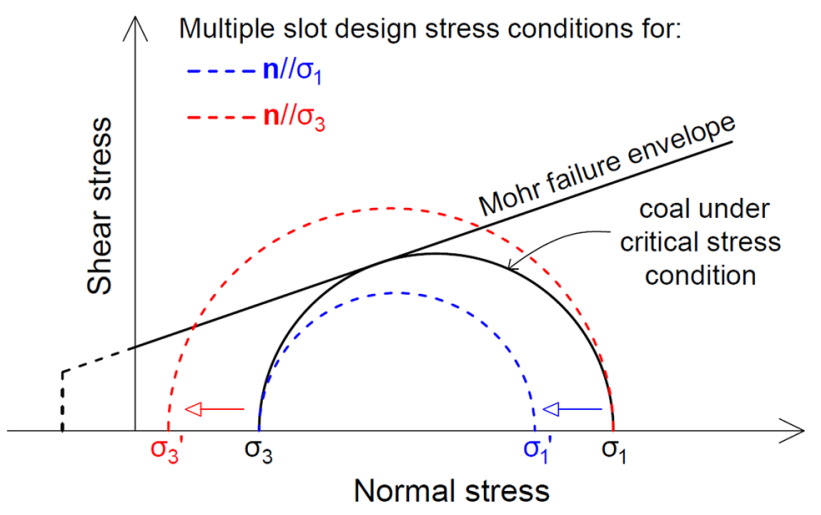

Fig. 21 The effect of varying slot spacing on the failure zone volume
The reduction of internal friction angle results in the decrease of failure envelope slope, which can disturb a substantial amount of elements resting with high confining stresses ( $\left.8 \mathrm{MPa} \leq \sigma_{3} \leq 14 \mathrm{MPa}\right)$. Compared with internal friction angle, the reduction of cohesion affects the failure envelope by reducing the intercept at $\sigma_{1}$-axis, which only has a moderate influence on the majority of intact elements. It is believed that the large sensitivity to $\varphi$ may be caused by the high in-situ stress condition or, more specifically, the minimum principal stress. If the majority stress states are in a lower stress range, for instance $2 \mathrm{MPa} \leq \sigma_{3} \leq 8 \mathrm{MPa}$, then the failure zone size may be more sensitive to the variation in cohesion, rather than the internal friction angle. 
Table 2 Parameters investigated in controlling slotting performance

\begin{tabular}{lllllll}
\hline Parameter & Unit & Baseline value & Variation range & $\begin{array}{l}\text { Variation } \\
\text { gradient }\end{array}$ & $\begin{array}{l}\text { Number of } \\
\text { scenarios }\end{array}$ & $\begin{array}{l}\text { Relationship with } \\
\text { failure zone size } \\
(V)\end{array}$ \\
\hline$C$ & $\mathrm{MPa}$ & 2.0 & {$[1.0,3.0]$} & 0.2 & 11 & Linear \\
$\varphi$ & $\circ$ & 30 & {$[20,40]$} & 2 & 11 & Power \\
$C_{\mathrm{r}}$ & $\mathrm{MPa}$ & 0.6 & {$[0.2,1.0]$} & 0.08 & 11 & Power \\
$\log \left(\varepsilon_{\mathrm{p}}\right)$ & - & -3.0 & {$[-4.0,-2.0]$} & 0.2 & 11 & Exponential to $\varepsilon_{\mathrm{p}}$ \\
$\mathbf{n} / / \sigma_{\mathrm{i}}$ & - & $i=1$ & $i=1,2,3$ & - & 3 & - \\
$R_{13}{ }^{\mathrm{a}}$ & - & 2.0 & {$[1.0,2.8]$} & 0.2 & 10 & Depends on $R_{23}$ \\
$R_{23}{ }^{\mathrm{a}}$ & - & 1.5 & {$\left[1.0, R_{13}\right]$} & 0.2 & 55 & Depends on $R_{13}$ \\
$D$ & $\mathrm{~m}$ & 0.5 & {$[0.3,0.7]$} & 0.04 & 11 & Binomial \\
$w$ & $\mathrm{~m}$ & 0.1 & {$[0.02,0.2]$} & 0.02 & 10 & Linear \\
$D / w$ & - & 5.0 & $1.7 ; 2.1 ; 3.0 ; 3.8$ & - & 8 & Linear \\
& & & $5.0 ; 6.8 ; 11.0 ; 19.5$ & & & \\
\hline
\end{tabular}

$C$ cohesion, $\varphi$ friction angle $C_{\mathrm{r}}$ residual cohesion, $\varepsilon_{p}$ plastic shear strain limit, $\mathbf{n}$ normal vector of a slot disk, $\sigma_{i}$ directions of principal stresses, $R_{13}$ ratio of maximum to minimum principal stress, $R_{23}$ ratio of intermediate to minimum principal stress, $D$ slot diameter, $w$ slot width, $D / w$ aspect ratio of a slot

aThese two parameters are dependent on each other and studied simultaneously

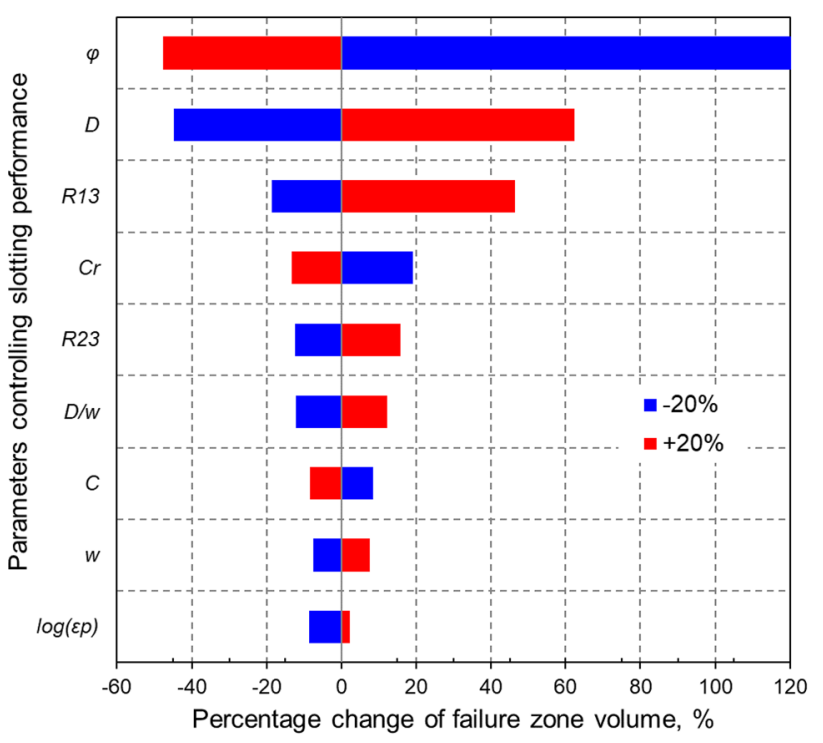

Fig. 22 Tornado chart illustrating the sensitivity of slotting performance to key parameters used in the analysis

The importance of slot diameter was also noted by $\mathrm{Lu}$ et al. (2011), in which they concluded that the increasing of slot diameter (denoted as 'slot depth' in their paper) can significantly increase the disturbance zone along and perpendicular to the borehole. The marginal effect of slotting width (denoted as 'slot thickness' in their paper) was also observed. But no quantitative relationship about the impact of these two parameters on slotting performance was given.

\section{Conclusions}

A systematic investigation on the sensitivity of slotting performance to a number of field and operational parameters was conducted via a series of numerical simulations. These parameters, referred to as key parameters here, include a wide range of geomechanical properties, in situ stress conditions, slot geometry and spacing. The relationships between individual parameters and failure zone size/volume induced by slotting were quantified. Internal friction angle, slot diameter and the ratio of the maximum principal stress to minimum principal stress were identified as the top three parameters in affecting slotting performance.

Model findings on slot diameter to width ratio $(D / w)$ confirmed the findings of Lin et al. (2015) and Yang et al. (2016) that the failure zone size is very sensitive to slot diameter, rather than its width. A large diameter slot has the advantage
Table 3 Top three key parameters controlling slotting performance

\begin{tabular}{lllll}
\hline $\begin{array}{l}\text { Parameter } \\
\text { ranking }\end{array}$ & Parameter & Symbol & $\begin{array}{l}\text { Correlation with fail- } \\
\text { ure zone volume }\end{array}$ & Relation with failure zone volume \\
\hline 1 & Friction angle & $\varphi$ & Negatively correlated & Power law \\
2 & Slot diameter & $D$ & Positively correlated & Binomial \\
3 & $\begin{array}{c}\text { Ratio of maximum to } \\
\text { minimum principal } \\
\text { stress }\end{array}$ & $R_{13}$ & Positively correlated & Parabolic (also depends on $R_{23}$ ) \\
& & & & \\
\hline
\end{tabular}




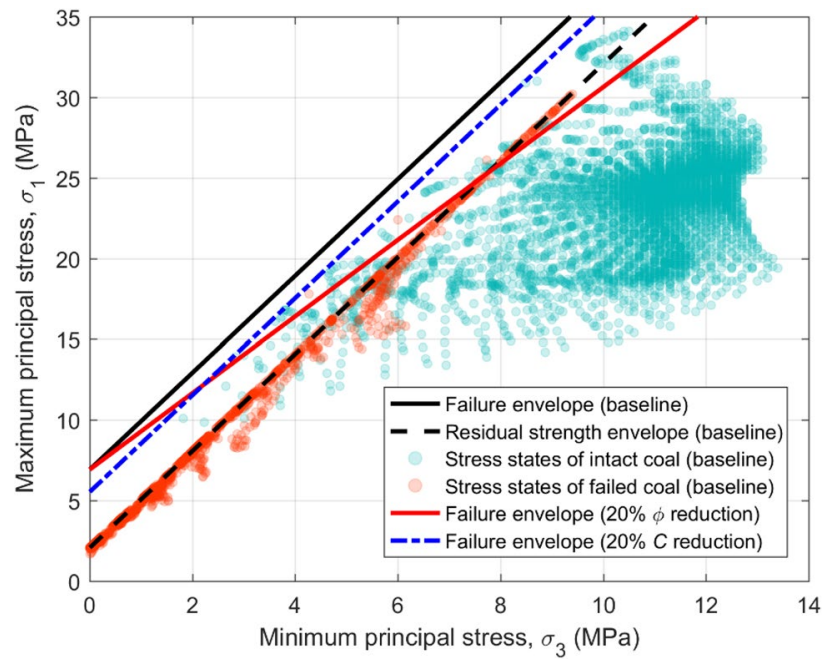

Fig. 23 Failure envelope variations with respect to the changes of cohesion and internal friction angle

of deep penetration into the coal seam, which creates a large surface area and a stress relief zone. On the other hand, a thick, but small diameter slot only cuts through an already stress relieved zone of a smaller dimension. Therefore, it is recommended to aim at creating a 'long and thin' rather than 'short and thick' slots to maximise the stimulated zone around a borehole.

The importance of in situ stress conditions in controlling slotting performance, which was mostly ignored in the past, was also investigated. It was found that relationship between $R_{13}$ and the failure zone volume is non-linear and depends on the level of intermediate principal stress $\left(R_{23}\right)$. In addition, it was found that the orientation of principal stresses with respect to the slot plane does not necessarily affect the size of the failure zone, but determines the shape of it, and the failure zone propagates along the direction of the lower principal stresses. Therefore, slotting operations in both in-seam and cross-measure boreholes need to consider the regional stress conditions around these boreholes carefully to maximise borehole stimulation impact.

The spacing of slotted boreholes and multi-slots in a single borehole need to honour the regional stress conditions. In general, denser slots or boreholes are required along the direction of the maximum principal stress. In areas where high deviatoric stresses are expected, the spacing of multiple slots in an individual borehole and the spacing between slotted boreholes do not need to be as dense as those required under near hydrostatic stress conditions.

Finally, it was found that elliptical slots have the potential to outperform circular slots under certain stress conditions. For example, approximately $12 \%$ increase in the failure zone size was observed when the long axis of the slot was parallel to the minimum principal stress $\left(a / / \sigma_{3}\right)$ and the long axis to short axis ratio was less than $5(a / b<5)$. These findings suggest that engineering elliptical slots in the field can lead to further improvements in stimulating slotted boreholes.

Acknowledgements This research was carried out as part of the project "Development of Improved Methane Drainage Technologies by Stimulating Coal Seams for Major Risks Prevention and Increased Coal Output (GasDRAIN)" funded by the European Commission Research Fund for Coal and Steel (RFCS), Grant No: RFCR-CT-2015-00005. The authors wish to thank the Hulleras Del Norte SA (HUNOSA) engineers Jose Raul González Ruizsanchez and Alexis Alonso Montes who have provided field and coal properties data for the Montsacro Colliery. The first author would also like to thank the Open Fund Project of State Key Laboratory of Coal Resources and Safe Mining (Grant No. SKLCRSM16KF02) for their support of his research.

Open Access This article is distributed under the terms of the Creative Commons Attribution 4.0 International License (http://creativeco mmons.org/licenses/by/4.0/), which permits unrestricted use, distribution, and reproduction in any medium, provided you give appropriate credit to the original author(s) and the source, provide a link to the Creative Commons license, and indicate if changes were made.

\section{References}

Aguado MBD, Nicieza CG (2007) Control and prevention of gas outbursts in coal mines, Riosa-Olloniego coalfield, Spain. Int J Coal Geol 69(4):253-266

Cheng YP, Wang L, Zhang XL (2011) Environmental impact of coal mine methane emissions and responding strategies in China. Int J Greenh Gas Control 5:157-166

Durucan S, Edwards JS (1986) The effects of stress and fracturing on permeability of coal. Min Sci Technol 3:205-216

Gao F, Xue Y, Gao Y, Zhang Z, Teng T, Liang X (2016) Fully coupled thermo-hydro-mechanical model for extraction of coal seam gas with slotted boreholes. J Natural Gas Sci Eng 31:226-235

Guo H, Yuan L, Shen B, Qu Q, Xue J (2012) Mining-induced strata stress changes, fractures and gas flow dynamics in multi-seam longwall mining. Int J Rock Mech Min Sci 54:129-139

Hoek E (2007) Practical rock engineering. Rock mass properties, p. 6. http://www.rocscience.com/education/hoeks_corner

Hoek E, Brown ET (1997) Practical estimates of rock mass strength. Int J Rock Mech Min Sci 34(8):1165-1186

Karacan C (2015) Analysis of gob gas venthole production performances for strata gas control in longwall mining. Int J Rock Mech Min Sci 79:9-18

Karacan C, Esterhuizen GS, Schatzel SJ, Diamond WP (2007a) Reservoir simulation-based modeling for characterizing longwall methane emissions and gob gas venthole production. Int J Coal Geol 71:225-245

Karacan C, Diamond WP, Schatzel SJ (2007b) Numerical analysis of the influence of in-seam horizontal methane drainage boreholes on longwall face emission rates. Int J Coal Geol 72:15-32

Kong S, Cheng Y, Ren T, Liu H (2014) A sequential approach to control gas for the extraction of multi-gassy coal seams from traditional gas well drainage to mining-induced stress relief. Appl Energy 131:67-78

Li X, Zhou D, Lu Y, Kang Y, Zhao Y, Wang X (2009) Dynamic effects of high-pressure pulsed water jet in low-permeability coal seams. J Coal Sci Eng (China) 15:284-288 
Lin B, Shen C (2015) Coal permeability-improving mechanism of multilevel slotting by water jet and application in coal mine gas extraction. Environ Earth Sci 73:5975-5986

Lin B, Yan F, Zhu C, Zhou Y, Zou Q, Guo C, Liu T (2015) Cross-borehole hydraulic slotting technique for preventing and controlling coal and gas outbursts during coal roadway excavation. J Natural Gas Sci Eng 26:518-525

Lin B, Zou Q, Liang Y, Xie J, Yang H (2018) Response characteristics of coal subjected to coupling static and waterjet impact loads. Int J Rock Mech Min Sci 103:155-167

Liu T, Lin B, Zou Q, Zhu C, Guo C, Li J (2015) Investigation on mechanical properties and damage evolution of coal after hydraulic slotting. J Natural Gas Sci Eng 24:489-499

Lu T, Yu H, Zhou T, Mao J, Guo B (2009) Improvement of methane drainage in high gassy coal seam using waterjet technique. Int $\mathrm{J}$ Coal Geol 79:40-48

Lu Y, Liu Y, Li X, Kang Y (2010) A new method of drilling long boreholes in low permeability coal by improving its permeability. Int J Coal Geol 84:94-102

Lu T, Zhao Z, Hu H (2011) Improving the gateroad development rate and reducing outburst occurrences using the waterjet technique in high gas content outburst-prone soft coal seam. Int J Rock Mech Min Sci 48:1271-1282

Papanastasiou P (2000) Localization of deformation and failure around elliptical perforations based on a polar continuum. Comput Mech 26(4):352-361

Shen C, Lin B, Sun C, Zhang Q, Li Q (2015) Analysis of the stresspermeability coupling property in water jet slotting coal and its impact on methane drainage. J Petrol Sci Eng 126:231-241

Si G (2015) An investigation into gas emission and outburst control in thick seam coal mining. Doctoral dissertation, Imperial College London
Si G, Jamnikar S, Lazar J, Shi JQ, Durucan S, Korre A, Zavšek S (2015a) Monitoring and modelling of gas dynamics in multi-level longwall top coal caving of ultra-thick coal seams, part I: borehole measurements and a conceptual model for gas emission zones. Int J Coal Geol 144:98-110

Si G, Shi JQ, Durucan S, Korre A, Lazar J, Jamnikar S, Zavšek S (2015b) Monitoring and modelling of gas dynamics in multilevel longwall top coal caving of ultra-thick coal seams, Part II: Numerical modelling. Int J Coal Geol 144:58-70

Si G, Durucan S, Shi JQ, Korre A, Cao W (2017) Key parameters controlling slotting operations to stimulate gas drainage performance in low permeability coal seams. In: Proc. 51st U.S. rock mechanics/geomechanics symposium, 25-28 June, ARMA-2017-0139, San Francisco

Somerton WH, Söylemezoḡlu IM, Dudley RC (1975) Effect of stress on permeability of coal. Int J Rock Mech Min Sci 12:129-145

Suárez-Ruiz I, Jiménez A (2004) Coal facies studies in Spain. Int J Coal Geol 58:31-39

Yang W, Lin B, Gao Y, Lv Y, Wang Y, Mao X, Wang N, Wang D, Wang Y (2016) Optimal coal discharge of hydraulic cutting inside coal seams for stimulating gas production: a case study in Pingmei coalfield. J Natural Gas Sci Eng 28:379-388

Zoback MD (2010) Reservoir geomechanics. Cambridge University Press, Cambridge, pp 132-133

Publisher's Note Springer Nature remains neutral with regard to jurisdictional claims in published maps and institutional affiliations. 